\title{
Endothelial dysfunction and platelet hyperactivity in type 2 diabetes mellitus: molecular insights and therapeutic strategies
}

CrossMark

\author{
Raminderjit Kaur ${ }^{1}$, Manpreet Kaur ${ }^{2}$ and Jatinder Singh ${ }^{*}$
}

\begin{abstract}
The incidence and prevalence of diabetes mellitus is rapidly increasing worldwide at an alarming rate. Type 2 diabetes mellitus (T2DM) is the most prevalent form of diabetes, accounting for approximately $90-95 \%$ of the total diabetes cases worldwide. Besides affecting the ability of body to use glucose, it is associated with micro-vascular and macrovascular complications. Augmented atherosclerosis is documented to be the key factor leading to vascular complications in T2DM patients. The metabolic milieu of T2DM, including insulin resistance, hyperglycemia and release of excess free fatty acids, along with other metabolic abnormalities affects vascular wall by a series of events including endothelial dysfunction, platelet hyperactivity, oxidative stress and low-grade inflammation. Activation of these events further enhances vasoconstriction and promotes thrombus formation, ultimately resulting in the development of atherosclerosis. All these evidences are supported by the clinical trials reporting the importance of endothelial dysfunction and platelet hyperactivity in the pathogenesis of atherosclerotic vascular complications. In this review, an attempt has been made to comprehensively compile updated information available in context of endothelial and platelet dysfunction in T2DM.
\end{abstract}

Keywords: Hyperglycemia, Insulin resistance, Inflammation, Oxidative stress, Vascular complications

\section{Background}

Diabetes mellitus (DM) is a chronic hyperglycemic disease condition attributed to defective insulin secretion or action or both [1]. According to World Health Organization (WHO), 1.5 million people died with DM in 2012. Moreover, more than $80 \%$ of the total deaths occurred due to DM are from low- and middle-income countries [2]. The prevalence of diabetes is also increasing very rapidly in India. According to International Diabetes Federation (IDF) (2017), 72 million cases of diabetes were reported from India with a prevalence of $8.8 \%$ [3]. Most of the cases with DM either have Insulin dependent DM (known as type $1 \mathrm{DM}$ ) or non-insulin dependent DM (known as type $2 \mathrm{DM}$ ).

\footnotetext{
*Correspondence: jatinterarora2009@gmail.com

${ }^{1}$ Department of Molecular Biology \& Biochemistry, Guru Nanak Dev

University, Amritsar, Punjab, India

Full list of author information is available at the end of the article
}

T2DM, also known as "adult-onset diabetes," is the most prevalent form of diabetes and accounts for approximately $90-95 \%$ of the total diabetes cases worldwide. T2DM is characterized by progressive insulin deficiency and impairment of $\beta$-cell function, superimposed on insulin resistance. It is a multisystem disease associated with both micro-vascular and macro-vascular complications. The micro-vascular complications include diabetic retinopathy, neuropathy and nephropathy [4]. The macro-vascular complications are manifested as accelerated atherosclerosis that results into severe peripheral vascular disease, premature coronary artery disease (CAD) and increased risk of cerebrovascular diseases [5-8]. Approximately $80 \%$ of the diabetic mortality is attributed to the thrombotic events, out of which $75-80 \%$ deaths are caused by cardiovascular complications. Moreover, patients with T2DM have two to four fold higher risk of recurrent atherothrombotic events and vascular complications as compared to non-DM patients $[9,10]$. 
The metabolic milieu of T2DM, including insulin resistance, hyperglycemia and release of excess free fatty acids, along with other metabolic abnormalities affects vascular wall by a series of events including endothelial dysfunction, platelet hyperreactivity, oxidative stress and low-grade inflammation. Activation of these events further enhances vasoconstriction and promotes thrombus formation, ultimately resulting in the development of atherosclerosis (Fig. 1) [6, 8]. The endothelial dysfunction is the key event that initiates the inflammatory mechanisms associated with vascular complications in T2DM patients [11]. Furthermore, it is an initial event of atherogenesis, which involves imbalance in the tightly regulated equilibrium of vasodilators and vasoconstrictors together with the inhibition of the anticlotting systems. These changes further impair vasorelaxation and increase proliferation of vascular smooth muscle cells [12]. Along with other contributors of prothrombotic state in T2DM, platelet dysfunction plays a pivotal role [13]. Activation of endothelium by increased release of cytokines and expression of adhesion molecules mediates platelet activation and adhesion to activated endothelium [13-16]. Impaired endogenous inhibition of platelets makes platelets more susceptible to activation and activated endothelium provides more adhesion molecules and platelet agonists. Activated platelets then mediate leukocyte recruitment, which in turn activated by subsequent interaction. Subsequently, after firm adhesion to activated endothelium, leukocyte transmigrates and presents to lipid and cells in vessel wall. This accelerates the further inflammatory reactions in the vascular wall and promotes atherosclerotic vascular complications [13-16]. Therefore, understanding of mechanism of endothelial and platelet dysfunction, unquestionably involved in pathogenesis of T2DM, is required to ameliorate the adverse vascular events, leading to prothrombotic state

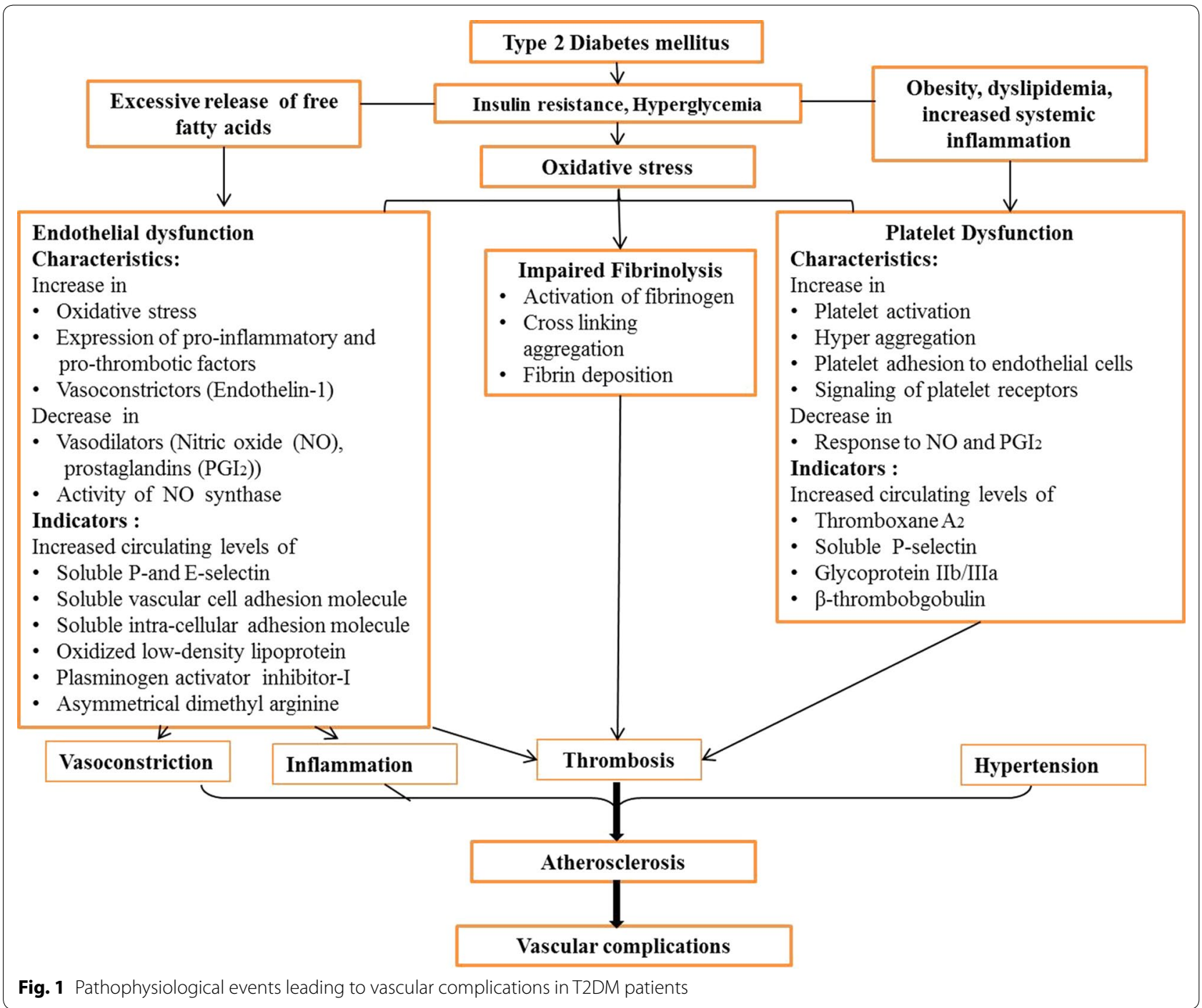


in T2DM. An attempt has been made to comprehensively compile updated information available in context of endothelial and platelet dysfunction in this chronic disease condition.

\section{Endothelial dysfunction in T2DM}

The endothelium comprises a single cell layer lining the inner surface of vascular lumen and act as a barrier between blood and vessel wall [17]. The endothelial cells perform multiple functions including regulation of cell adhesion, tissue growth and metabolism, angiogenesis, inflammatory responses, vessel integrity, hemostasis, vascular permeability, vascular smooth muscle cell proliferation, platelet activation, fibrinolysis, thrombus formation and maintaining blood fluidity [18-21]. Endothelium is also responsible for maintaining vascular tone by production of vasodilators including nitric oxide (NO) and prostacyclin $\left(\mathrm{PGI}_{2}\right)$, and vasoconstrictors like endothelin-1 (ET-1), angiotensin II and reactive oxidative species (ROS) [22-24]. Endothelial cells also release prothrombotic molecules including von Willebrand factor (vWV) (promotes platelet aggregation), plasminogen activator inhibitor-1 (PAI-1) (inhibits fibrinolysis) and antithrombotic molecules including $\mathrm{NO}$ and $\mathrm{PGI}_{2}$ (inhibit platelet aggregation) [19].

\section{Hyperglycemia and endothelial dysfunction}

Studies have shown that impaired endothelial function in both macro- and micro-vascular complications owing to prolonged, transient and acute hyperglycemia in animal models as well as human participants [25-28]. Although, effects of intensive glycemic control were well profound for prevention of micro-vascular complications as compared to macro-vascular disease reduction [29]. Hyperglycemia is thought to trigger vascular damage by creating imbalance between NO bioavailability and accumulation of ROS as well as reactive nitrogen species (RNS, resulting in endothelial dysfunction) (Fig. 1). Furthermore, hyperglycemia damage the vascular bed by several cellular mechanisms, comprising of enhanced production of intracellular advanced glycation end products (AGEs), increased expression of AGE receptors (RAGE) and ligands, augmented polyol and hexosamine flux, activation of protein kinase $\mathrm{C}$ (PKC) and over activation of hexosamine pathway [30]. The main underlying pathway is oxidative stress. Furthermore, in vivo and in vitro studies have shown that chronic levels of oxidative stress are among the earliest abnormalities in the natural history of insulin resistance and T2DM [31-34]. However, there is scarcity of data regarding oxidative stress in T2DM in human participants [35-38]. In a recent study, biomarkers of oxidative stress i.e. oxidized LDL and F2-isoprostanes, have been shown to be positively correlated with incident T2DM, whereas this association was attenuated with adjustment for BMI [39]. Increased ROS impairs glucose metabolism by glycolysis and increase its flux through alternative polyol and hexosamine pathways [40]. Furthermore, hyperglycemia mediated oxidative stress induces DNA damage and production of ADP-ribose polymer by activation of nuclear poly (ADP-ribose) polymerase (PARP) and reduction of glyceraldehyde-3-phosphate dehydrogenase activity. This eventually increases the levels of all the upstream glycolytic intermediates that trigger above mentioned various damaging mechanisms. The overall consequences of these mechanisms are increased vascular permeability, oxidative stress and apoptosis. Hyperglycemia also activates nuclear factor- $\mathrm{kB}(\mathrm{NF}-\mathrm{kB})$ that mediates low-grade vascular inflammation $[7,30$, 41]. Furthermore, NF- $\mathrm{kB}$ activation leads to augmented production of vascular adhesion molecules, cytokines and chemo-attractants resulting in activation of inflammatory cells in vascular wall. Additionally, glucotoxicity leads to increased expression of coagulant tissue factors like PAI-1, resulting in a prothrombotic state. Along with hyperglycemia, dyslipidemia and hyperinsulinemia also affect vascular tone through imbalance of vascular tone regulators [42] (Fig. 2).

AGEs formation further lead to alteration of structural, functional and receptor recognition properties of matrix components. Sequentially, AGEs binding to its receptor (RAGE) increases superoxide production that promotes macrophage induced vascular inflammation [43-45]. Furthermore, AGEs also induces decreased endothelial NO synthase (eNOS) expression as well as NO synthesis and increased ET-1 expression, leading to endothelial dysfunction [46-48]. Thus, under hyperglycemic conditions, altered formation of various biochemicals including AGEs, ROS, RNS, 3-deoxyglucosone, Amadori products, diacylglycerol and methylglyoxal, significantly contributes to endothelial dysfunction in diabetic patients [49].

An association was observed between good glycemic control and improved microvascular function in recently diagnosed T2DM patients with CVD [50]. However, in patients with prolonged disease duration, this association was lost. Furthermore, Dextrose-mediated hyperglycemia led to impaired endothelial cell proliferation as well as migration in Human umbilical vein endothelial cells by inhibiting the activation of ERK, p38 and Akt pathways [51]. These events were mitigated by co-incubation with HDL, indicating the protective effect of HDL in impaired glucose homeostasis [51]. Furthermore, HDL has also shown to have 


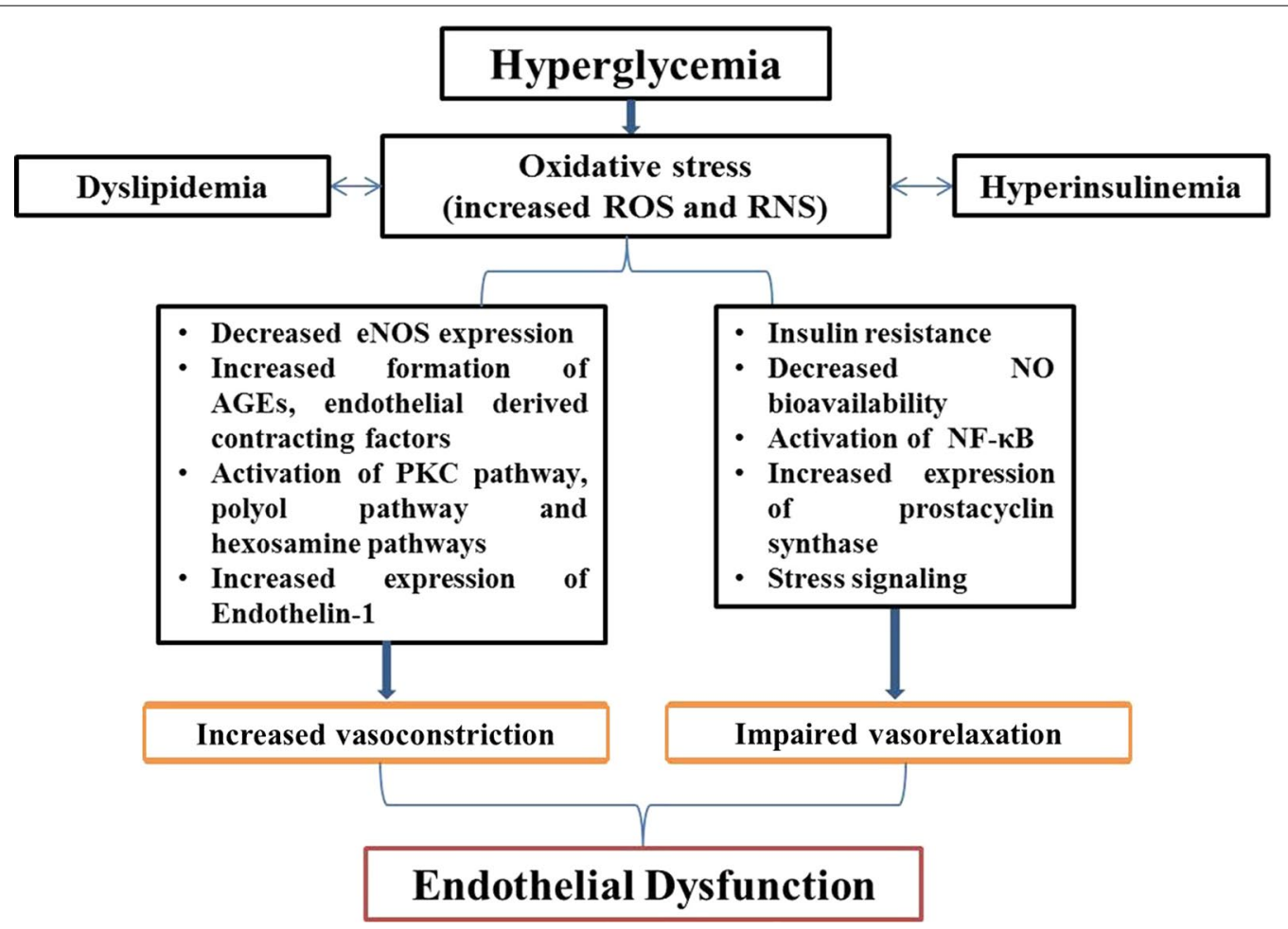

Fig. 2 Endothelial dysfunction in diabetes: Hyperglycemia leads to increase production of ROS and RNS resulting oxidative stress. Oxidative stress affects vascular homeostasis by causing increased vasoconstriction and impaired vasorelaxation and eventually leads to endothelial dysfunction. $R O S$ reactive oxygen species, RNS reactive nitrogen species, eNOS endothelial nitric oxide synthase, NO nitric oxide, AGE advanced glycation end products, PKC protein kinase, NF-KB nuclear factor-KB

anti-inflammatory properties through suppression of pro-inflammatory cytokines and cell adhesion molecules, which can reduce endothelial activation. However, anti-inflammatory capacity of HDL was shown to be markedly impaired in T2DM patients, which can be partially attributed to chronic hyperglycemia, persistent low grade inflammation and reduced serum paraoxonase/arylesterase 1 (PON-1) activity [52]. This decrease in anti-inflammatory protection capacity of HDL leads to increased atherosclerosis risk in T2DM patients [53]. Furthermore, glucose fluctuation were also reported to contribute to chromatin remodeling and may describe the persistent vascular dysfunction in uncontrolled T2DM (HbA1c $>7.5 \%$ [54]. In addition, microRNA, miR-29, is reported to play an important role in maintaining normal endothelial function by inducing NO production. miR-29 expression has been shown to be deregulated in T2DM patients [55]. Intraluminal delivery of miR-29a-3p or miR-29b-3p mimics restored normal endothelium-dependent vasodilation (EDVD) in these patients, which otherwise showing impaired EDVD. These evidences suggested the therapeutic potential of miR-29 against cardiometabolic disorders.

\section{Insulin resistance and endothelial dysfunction}

Insulin resistance, a key feature of T2DM, is characterized by the reduced ability of insulin to promote glucose uptake in multiple organs including skeletal muscle, adipose tissue and heart, and to restrain hepatic glucose output $[55,56]$. Insulin resistance often preceded onset of hyperglycemia and diabetes for many years [57]. Obesity is a pivotal factor in increasing incidence and prevalence of insulin resistance and its vascular complications [58]. Insulin signaling involves two major pathways i.e. Phosphatidylinositol-3-kinase (PI3K) dependent pathway responsible for metabolic and hemodynamic effects and mitogen activated protein kinase (MAPK)-dependent pathway for regulation of gene expression, differentiation and cell growth. Generally, insulin promotes NO production by activating eNOS through PI3K-dependent pathway and ET-1 secretion via MAPK-dependent pathway $[59,60]$. Under the conditions of insulin resistance, PI3K pathway is impaired, resulting in decreased NO production and MAPK pathway is activates, leading to increased production of ET-1, ultimately resulting in endothelial dysfunction [61]. Insulin resistance also increases expression of PAI-1, a coagulant tissue factor and adhesion molecules [62]. 
Additionally, insulin resistance stimulates the proliferation of vascular smooth muscle cells (VSMCs) and excessive release of free fatty acids (FFAs) in adipose tissue, which subsequently increase oxidative stress and PKC activation [63]. Insulin resistance induced excessive release of FFAs is further involved in the development of pro-atherogenic lipid profile and dyslipidemia. Eventually, increased serum levels of PAI-1, ET- 1, tumor necrosis factor- $\alpha$ (TNF- $\alpha$ ), interleukin-6 (IL-6), and C-reactive protein (CRP), reflect association of insulin resistance with low-grade inflammation and endothelial dysfunction $[63,64]$.

In past years, the usefulness of Homeostasis model assessment of insulin resistance (HOMA-IR), as an index of insulin resistance in T2DM patients, has become a focus of much attention [65-67]. In addition, insulin resistance assessed by HOMA-IR, in non-diabetic patients with chest pain and without myocardial perfusion defects, was also shown to be associated with endothelial dysfunction, conferring independent prognostic information [68]. Furthermore, insulin resistance adipocyte-derived exosomes (IRADEs) have been shown to promote plaque vulnerability and plaque burden, partly through sonic hedgehog (shh), by mediating vasa vasorum angiogenesis in diabetic ApoE-1-mice. These effects were attenuated by silencing of shh gene and this approach has been suggested as a novel therapeutic strategy in treatment of diabetic atherosclerosis [69].

\section{Excessive free fatty acids and endothelial dysfunction}

Increased circulating levels of FFAs are attributed to excessive release from adipose tissue and reduced uptake by skeletal muscles $[70,71]$. In vivo as well as studies including human participants have suggested the acute infusion of FFAs diminishes endothelium-dependent vasodilation [7, 72]. Excessive FFAs may cause lipotoxicity that impair normal endothelial function by same mechanisms and to the same extent as by glucotoxicity. FFAs induce vasculature ROS production by increasing the expression and protein content of NADPH oxidases, and via mitochondrial uncoupling $[30,63]$. It also stimulates excessive superoxide production, leading to inactivation of important anti-atherogenic enzymes i.e. eNOS and $\mathrm{PGI}_{2}$ synthase. FFA-induced ROS production resulted into decreased concentration of intracellular glutathione, making vasculature more susceptible to oxidative damage. It also activates NF- $\mathrm{KB}$, leading to the activation of inflammatory cascade [73-75]. FFAs activate IKK $\alpha$, which impairs insulin-induced production of eNOS and NO in endothelial cells [76]. Furthermore, FFAs also activates PKC that leads to increased serine phosphorylation of insulin resistance substrate (IRS)-1, resulting into decreased activation of phosphoinositide-dependent kinase-1, PI-3K, Akt, and eNOS, and ends up with impaired endothelium NO production [77, 78]. Eventually, increased FFAs lead to decreased NO bioavailability, increased vascular oxidative stress, endothelial apoptosis and augmented inflammation [79]. In diabetes, insulin resistant visceral adipocytes augment influx of FFA in arterial endothelial cells that further activate metabolite sensitive pathways of vascular damage. This may explain a link between insulin resistance and macrovascular diseases [30, 80]. Furthermore, insulin resistance increase oxidation of fatty acids, which leads to augmented oxidative stress in diabetic macrovasculature, while increased hyperglycemia-derived ROS production in diabetic microvascular diseases. Thus, oxidative stress seems to be a common pathway for triggering vascular dysfunction in both types of diabetic vascular complications [81, 82].

\section{Assessment and biomarkers of endothelial dysfunction in T2DM}

Generally, endothelial dysfunction is evaluated by assessing NO-dependent endothelium relaxation i.e. vasodilation. In macrocirculation, endothelial function can be estimated by measuring coronary artery diameter after intra coronary infusion of agonists (e.g. acetylcholine) by quantitative angiography and at microcirculation level by assessing change in blood flow through intravascular ultrasound [83, 84]. This method is regarded as "gold standard" technique for assessment of endothelial function and has the highest clinical value, since it is used to assess the vascular bed involving atherosclerosis process and cardiac events. As forearm blood flow is invasive, another method was introduced in past decades that involve flow-mediated dilatation (FMD) of the brachial artery in response to shear stress. In this technique, changes in arterial diameter are measured by high resolution doppler ultrasonography. Escalating and deflating a blood pressure cuff was used to induce blood flow in brachial artery by shear stress (reactive hyperemia). Peripheral endothelial function is assessed using finger plethysmography by following same principle. Another technique, peripheral arterial tonometry (EndoPAT) is used to record increased digital pulse amplitude in response to reactive hyperemia and it follows the same principle of endothelial-induced vasodilatory response to acetylcholine $[18,85]$. Furthermore, various agents/intervention induced capillary blood flow in several vascular beds, increasing endothelial-mediated blood flow is monitored by positron emission tomography (PET) [86-88].

Moreover, increased levels of biomarkers of inflammation, oxidative stress and hemostasis including levels of soluble inter-cellular adhesion molecule (sICAM-1), soluble vascular cell adhesion molecule (sVCAM), soluble 
P-selectin (sP-selectin), soluble E-selectin (sE-selectin), asymmetrical dimethylarginine (ADMA), oxidized lowdensity lipoprotein (oxLDL), PAI-1, vWF and CRP are used as important indicators for endothelial function [11, 84, 89]. Furthermore, overexpression of ET-1 was reported to exaggerate diabetes-induced endothelial dysfunction by altering oxidative stress [90]. Moreover, interaction between TNF- $\alpha$ and IL- 6 also exacerbate oxidative stress and reduce phosphorylation of eNOS, contributing to increase endothelial dysfunction in T2DM patients [91].

\section{Pharmacological influences on endothelial function and its biomarkers}

Recent studies have recognized signaling of winglesstype family member (Wnt) 5 a through c-jun $\mathrm{N}$-terminal kinase (JNK) as a metabolic dysfunction regulator with potential significance to vascular function $[92,93]$. Furthermore, it was observed that noncanonical Wnt5a signaling and JNK activity may contribute to vascular insulin resistance as well as endothelial dysfunction and may represent a novel therapeutic target to protect the vasculature in patients with diabetes mellitus [94]. Furthermore, endothelium possess a limited inherent selfrepair ability because of being formed from terminally differentiated cells of low proliferative potential, called as endothelial progenitor cells (EPCs). Previous studies have stated the prime role of EPCs in progression and development of vascular complications in T2DM patients [95, 96]. Another study has demonstrated effects of chronic administration of phosphodiesterase inhibitors on endothelial markers in T2DM patients [97]. In this study, beneficial effects of chronic use of PDE5i on endothelial function were observed. Furthermore, chronic administration of Sildenafil was found to improve serum pro-inflammatory maker (IL-6) and hemodynamic parameter (FMD) T2DM patients. Moreover, another study has reported the role of impaired autophagy in endothelial dysfunction in diabetic patients, which may be considered as a therapeutic target for diabetic vascular compilations [98]. In endothelial cells, eNOS uses L-arginine to produce $\mathrm{NO}$, where arginase utilizes $\mathrm{L}$-arginase to produce ornithine and urea $[99,100]$. In addition, arginase up-regulation has been shown to reduce NO production by reducing bioavailability of L-arginine to eNOS, thus playing an important role in vascular dysfunction in diabetes [101]. Furthermore, endothelial function was reported to be improved in T2DM patients, without changes in HbA1c levels, by intervention with a fiber-rich diet with brown rice possibly through reduction of postprandial glucose excursions [102]. Furthermore, activation of nuclear factor (erythroid-derived 2)-like 2 (Nrf2), a ubiquitously expressed redox sensitive transcription factor, has been shown to attenuate endothelial dysfunction, along with downregulation of inflammatory as well as pro-oxidant genes and reduction of leukocyte-endothelial interactions [103-107]. This represents a novel therapeutic approach to inhibit diabetes related vascular injury. Furthermore, a study including diabetic patients has suggested that arginase inhibitors may prevent the endothelial dysfunction and maintain $\mathrm{NO}$ levels in these patients [108]. Moreover, Ipragliflozin (a novel selective sodium-glucose cotransporter 2 (SGLT2) Inhibitor) has been shown to improve hyperglycemia and prevent the development of endothelial dysfunction in a streptozotocin-induced diabetic mouse [109]. Furthermore, another SGLT2 Inhibitor, dapagliflozin have shown to reduce blood pressure and improve glycemic control in T2DM patients [110-112]. In addition to this, acute administration of dapagliflozin resulted into significantly improved systemic endothelial function, renal resistive index, arterial stiffness and parameters associated with the early stages of vascular remodeling $[110,113]$. Moreover, as add-on therapy to metformin for 16 weeks, dapagliflozin improves FMD assessed endothelial function in patients with inadequately controlled early-stage T2DM [114]. Additionally, dipeptidyl peptidase inhibitors (such as linagliptin and voglibose), one of the recently introduced classes of oral glucose-lowering drugs, has been shown to significantly improve microvascular function in the fasting state and ameliorate cardiometabolic and renal parameters in the newly diagnosed T2DM and CAD patients $[115,116]$. Furthermore, various crosssectional studies have observed elevated levels of ADMA in T2DM Patients with macrovascular diseases [117, 118]. Moreover, ADMA is suggested as an independent risk factor for mortality and CVD in a wide spectrum of populations $[119,120]$. As mentioned previously, accelerated atherosclerosis in T2DM is also associated with decreased activity of PON-1. Rosuvastatin, a class of statins, was shown to improve microvascular reactivity with associated beneficial changes in the postprandial levels of ADMA and PON-1 [121]. Furthermore, a continuous intravenous infusion of glucagon-like peptide-1 (GLP-1) analogs was reported to improve the blood glucose-independent vascular endothelial dysfunction in T2DM patients with stable CAD [122]. Moreover, exenatide (GLP-1 analog) was shown to inhibit the postprandial vascular endothelial dysfunction and was suggested to have multiphasic anti-atherogenic actions involving not only glucose but also lipid metabolism [123]. It was also reported that GLP-1 receptors are expressed on vascular endothelial cells and directly increase the production of $\mathrm{NO}$ and restrict the expression of endothelial cell adhesion factors [124, 125]. Furthermore, Biomarkers of inflammation and endothelial dysfunction such as 
ICAM-1 and E-selectin were observed to be positively correlated with incident T2DM, adding to the estimation of T2DM beyond a common risk score [126]. Additionally, circulating microparticles (endothelial- and platelet derived) levels have been proposed to be one of the important procoagulant determinants in T2DM patients [127]. Levels of endothelial- derived microparticles such as $\mathrm{CD}_{105^{+}}$, PECAM-1, 62 $\mathrm{E}^{+}$and $\mathrm{CD} 106^{+}$as well as platelet-derived microparticles including P-selectin, fibrinogen, TF have been reported to be significantly higher in T2DM patients as compared to healthy controls [79, 128-130]. Furthermore, miRs (miR-320, miR-221, miR-222, miR-503, miR-126), a class of small non-coding RNAs, are suggested to play an important role in pathogenesis of vascular damage induced by hyperglycemia [131, 132]. Various microarray studies have observed the altered expression of miRs in T2DM patients [132134]. A recent study has shown the critical involvement of miR-503 in hyperglycemia-induced endothelial dysfunction in diabetic mice and up-regulation of ischemic limb muscles in diabetic subjects. Remarkably, inhibition of miR-503 resulted in normalization of post-ischemic neovascularization and blood flow recovery in these diabetic mice [135]. Furthermore, numerous studies have shown decreased plasma concentration of adiponectin (APN), a multifunctional adipocytokine of adipose tissue, in T2DM patients, indicting its important role in pathogenesis of T2DM [136-138]. Additionally, T-cadherin (T-cad), a unique member of the cadherin family, has been identified as an important receptor of APN [139-142]. A recent in vivo study has shown that T-cad deficiency may cause endothelial dysfunction in T2DM vascular segments, suggesting an important role of $\mathrm{T}$-cad in pathogenesis of T2DM. Therefore, altering T-cad deficiency may represent another potential therapeutic strategy in the amelioration as well as prevention of vascular injury in the T2DM [143].

\section{Platelets hyperactivity in T2DM}

Platelets were first discovered in 1882 by Giulio Bizzozer and the multifunctional attributes of platelets were remained source of interest for biologists for many years [144]. Platelets are mainly involved in hemostasis by initiating the blood coagulation mechanism. Preferably, these remain in inactive state and only get activated by a vascular injury. On activation, platelets release several prothrombotic components from their granules through aggregation. These components including coagulation factor V, fibrinogen and vWV. Activated platelets showed altered expression of various surface glycoproteins (GP). In this activation phase, P-selectin, an adhesion molecule, stored in Weibel Palade bodies of endothelial cells and $\alpha$ granules of platelets is translocated to the surface
[145]. GPIIb-IIIa, present on surface of activated platelets, undergoes conformational changes by activation and binds to fibrinogen. In these thrombin-activated platelets, binding of GPIV to thrombospondin (GP with antiangiogenic function) is increased, while binding sites of the vWF on GPIb-IX complex gets down-regulated [146].

To prevent thrombus formation, endothelium regulate the activity of proaggregants (such as thrombin, collagen, $\mathrm{ADP}$ and $\mathrm{TxA}_{2}$ ) and releases some antiaggregants, such as $\mathrm{NO}$ and $\mathrm{PGI}_{2}$ in normal blood vessels [147]. In contrast to proaggregants which show their effects after binding to specific platelet surface receptor, NO crosses the membrane and induce the production of guanylate cyclase. Various disease conditions such as diabetes, atherosclerosis, hypertension and heart disease show a common risk characteristic i.e. high thrombus formation due to increased platelet activity. Researchers believe that platelet hyperactivity may occur due to procoagulant mechanisms as well as loss of the preventive effect of antiaggregants. Additionally, platelet resistance against suppressive effect of insulin and decreased secretion of antiaggregants (including $\mathrm{NO}$ and $\mathrm{PGI}_{2}$ ) by endothelium, resulting in loss of platelet control as well as its contact with endothelium [148]. Probably, various mechanisms involved in regulation of platelet activity including platelet-vascular wall contact platelet-agonist relation, platelet-coagulation factor relationship and platelet-platelet interface been suggested to be impaired [148].

In diabetes, several factors including impaired fibrinolysis, increased coagulation, endothelial dysfunction and platelet hyperreactivity, contribute to the prothombic condition that describes patients with T2DM $[7,13,15$, $16,49,149,150]$. Platelets are characterized to be hyperactive with increased activation, adhesion and aggregation due to dysregulation of several signaling pathways in T2DM patients [7, 13-16, 151]. Platelets involve in disease pathology by not only triggering thrombus formation but also by releasing oxidative, mitogenic and vasoconstrictive substances that induce the development of local vascular lesions. Furthermore, elevated baseline activation and platelet hyperreactivity in diabetic patients are associated with various metabolic conditions like hyperglycemia, insulin resistance, obesity, dyslipidemia, increased systemic inflammation and oxidative stress [13-16].

\section{Hyperglycemia and platelet hyperactivity}

As mentioned already, hyperglycemia plays important role in development of various vascular abnormalities leading to prothrombotic state of diabetic patients $[152,153]$. A number of mechanisms are associated with hyperglycemia to increase the platelet reactivity (Fig. 3). 


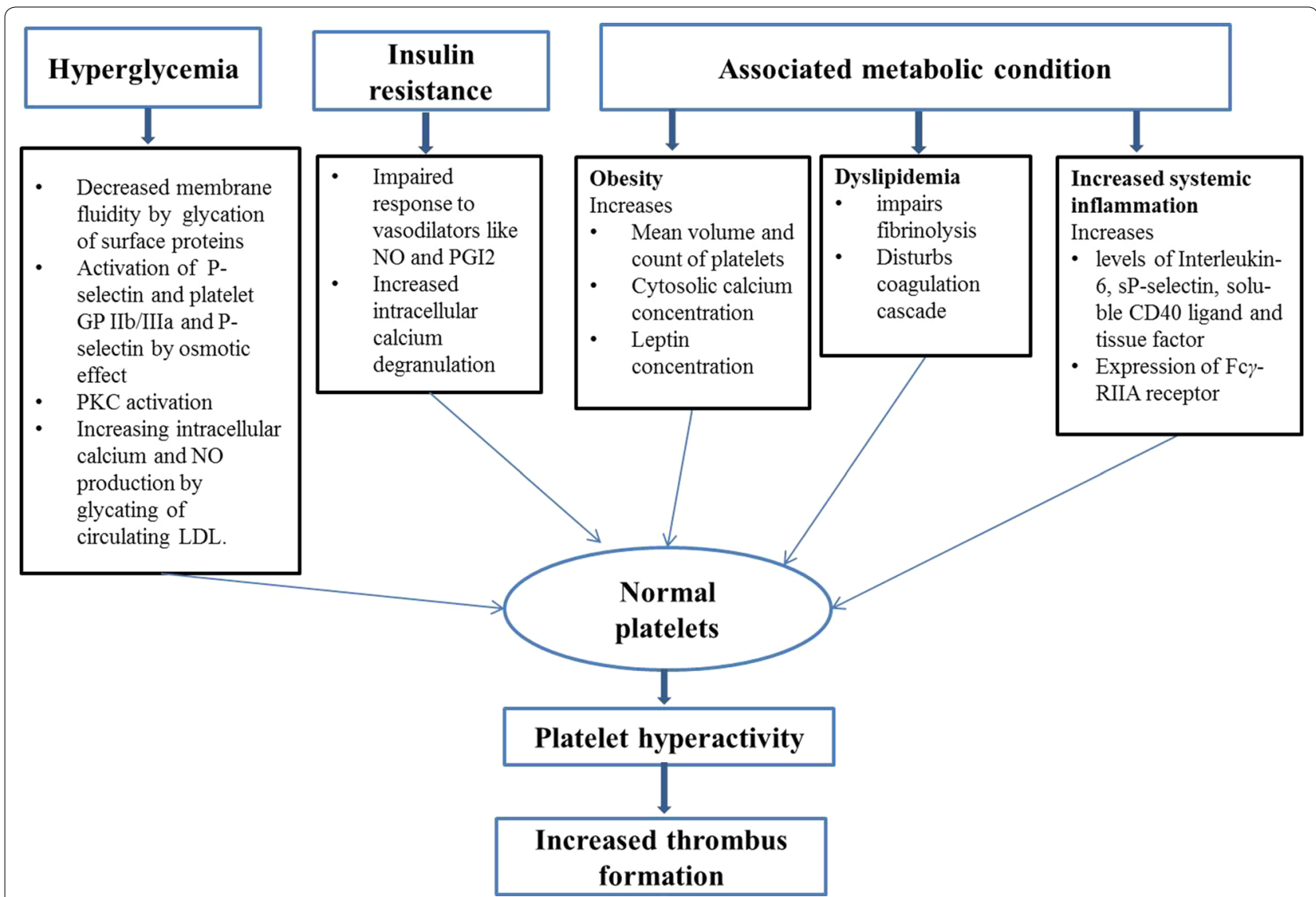

Fig. 3 Schematic representation of various biochemical factors responsible for platelet hyperactivity in T2DM

The first mechanism is glycation of platelet surface proteins, which increase platelet adhesion by impairing fluidity of membrane [154, 155]. Furthermore, exposure to hyperosmolarity activates platelet GP IIb/IIIa and P-selectin expression, suggesting that hyperglycemia may have direct osmotic effect [156]. Moreover, both chronic and acute hyperglycemia also induces in vivo PKC activation, a transduction pathway that triggers platelet activation [157]. Unlike in healthy subjects, platelets from diabetic patients in vitro also show temporary calcium-sensitive $\mathrm{PKC} \beta$ isoenzyme activation under acute hyperglycemia, even without any additional stimuli, demonstrating inherent diabetes-associated impairment of this pathway. In addition, glycation of circulating LDL results in augmented No production and increased intracellular calcium concentration [158]. Specifically, hyperglycemia induces coagulation mechanism by increasing release of prothrombotic molecules like vWF and tissue factor, while inhibits fibrinolysis by raising PAI-1 concentration $[159,160]$.

Furthermore, platelets are characterized by increased expression of adhesion molecules in T2DM. Platelets of T2DM patients have augmented expression of platelet activation markers (CD31, CD49b, CD62P and CD63) as compared to healthy individuals $[161,162]$. A significant reduction in expression of these markers was noticed with improved metabolic control. Moreover, a significant association was observed between glycated hemoglobin (HbA1C) levels and CD62P as well CD63. The above findings suggest that improving glycaemic control can be helpful in reducing platelet adhesion and activation $[161,162]$. Occurrence of acute hyperglycemia in healthy subjects, may results into increased platelet activation and reactivity, evidenced by elevated levels of surface (P-selectin and CD40 ligand) as well as soluble markers (sP-selectin) [162-165]. Furthermore, P-selectin expression was found to be associated with fasting glucose and $\mathrm{HbA} 1 \mathrm{C}$, suggesting that platelet activity can be reduced by improved glycemic control in T2DM patients with coronary angioplasty [162].

\section{Insulin resistance and platelet hyperactivity}

Impaired insulin action is a prime factor for the development of T2DM $[15,166]$. In prediabetes, pancreatic $\beta$-cells produce compensatory increased insulin to maintain fasting euglycemia. In predisposed individuals, under 
increased insulin demand, the pancreatic $\beta$-cells undergo apoptosis, resulting in $\beta$-cell mass reduction. Eventually, increased insulin in prediabetic condition gradually leads to relative and absolute insulin deficiency. Platelet functions are directly controlled by insulin through a functional insulin receptor (IR) present on platelet surface [167]. The Impact of hyperinsulinemia on platelets is complex and varying between patients with insulin resistance and healthy individuals. In healthy individuals, binding of insulin to IR in vitro leads to translocation of magnesium to platelets, resulting into reduced platelet aggregation and decreased release of proaggregatory agents (e.g. thromboxane B2) [168]. Along with other effects on platelets, insulin induces plasminogen activator secretion and increases expression of $\mathrm{PGI}_{2}$. Furthermore, insulin binding to IR located on platelets activates insulin receptor substrate 1 (IRS-1) via tyrosine phosphorylation and mediates its association with Gi $\alpha$-subunit $[169,170]$. This leads to decreased activity of Gi, which in turn impairs tonic cAMP suppression, raises intraplatelet cAMP levels, reducing signaling of P2Y12 and resulting into decreased platelet activity (Fig. 4). It is also suggested that the relevance of these effects can be restricted by dimerization of subunits of IR and insulin-like growth factor 1 (IGF-1) receptor [171]. Alike IR, IGF-1 receptors are also expressed in platelets [172]. However, binding of IGF-1 to the IGF-1 receptor leads to activation of downstream IR mediators (IRS-1 and IRS-2), resulting in increased platelet reactivity [173]. Moreover, previous in vivo studies involving healthy individuals have proposed that insulin impairs platelet interaction and collagen and also reduces its sensitivity to proaggregants [169, 174].

\section{Oxidative stress and platelet hyperactivity}

As already mentioned, patients with T2DM have been reported to have increased oxidative stress. In these patients, oxidative stress increases intra platelet calcium concentration by platelet activation and facilitating platelet aggregation response [43]. Increased oxidative stress, mainly in uncontrolled T2DM, may leads to platelet hyperactivity by three different ways. Firstly, by increasing production of $\mathrm{F} 2$ isoprostane (prostaglandin like compound considered as a marker of oxidative stress), which

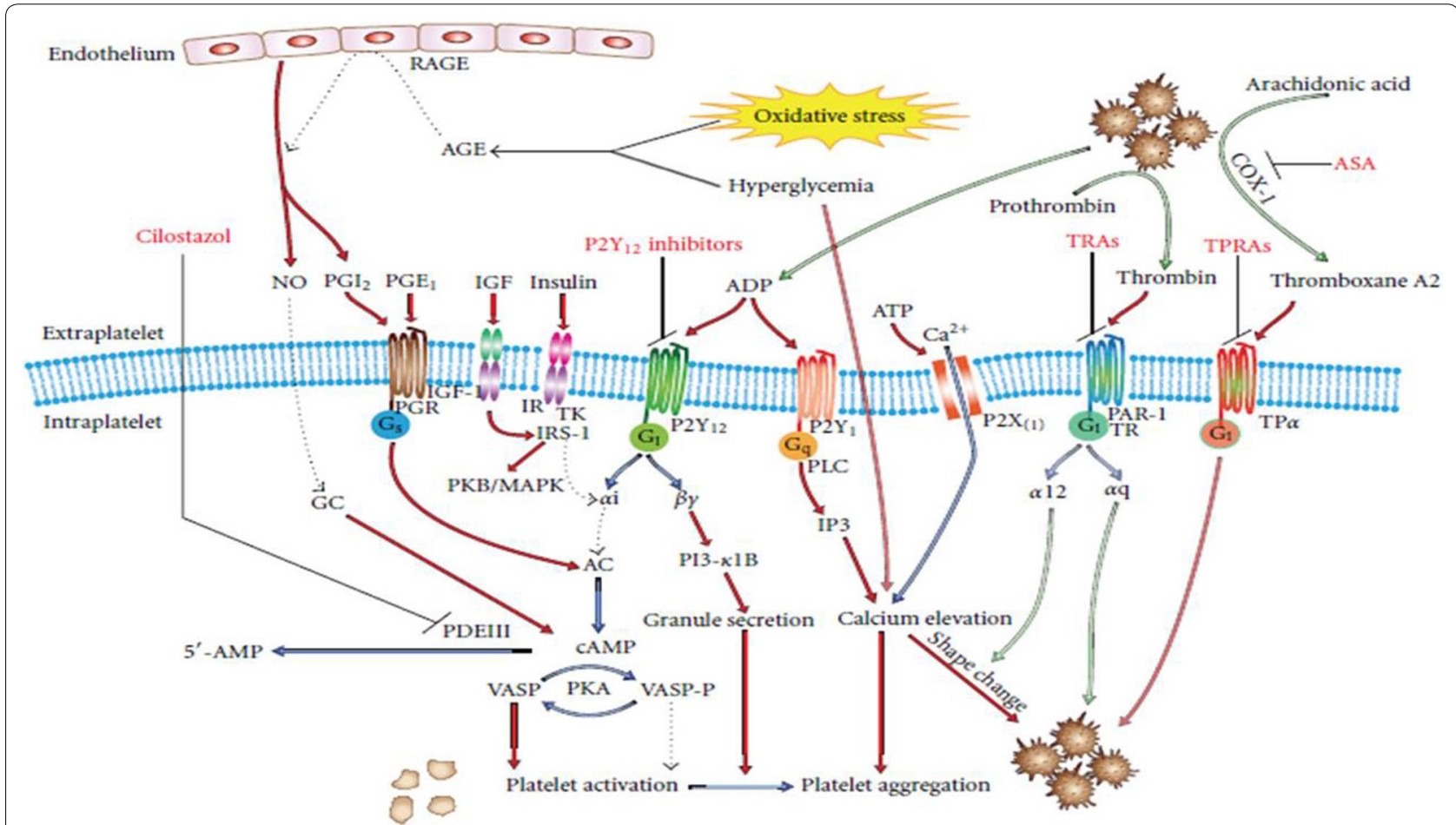

Fig. 4 Mechanisms responsible for platelet hyperreactivity in T2DM patient: Elevated cAMP levels leading to platelet inhibition via CAMP-dependent protein kinase (PKA), which disrupt signaling via receptor activation, thromboxane A2 production, MAPK pathway, activation of PKC. The transmembrane G-protein associated receptors involved are prostaglandin, P2Y, P2X, TR, and TP. Both TR and TP present novel drug targets. Antiplatelet drugs are shown in red. NO nitric oxide, AGE advanced glycation end products, RAGE AGE receptors, PKA/B/C protein kinase A/B/C, TK tyrosine kinase, Pl-3 phosphoinositol-3 kinase, MAPK p38 mitogen-activated protein kinase, GC guanylate cyclase, PAR-1 protease activated receptor, $T R$ thrombin receptor, TPa thromboxane receptor, TRA thrombin receptor antagonist, TPRA thromboxane receptor antagonist, ASA acetylsalicylic acid (aspirin) (Adapted from Kakouros et al. [16]) 
may enhance platelet response to agonists. Secondly, by reduction activity of eNOS, leading to decreased NO production. The last way is by increasing signaling of platelet receptors [175].

\section{Other metabolic conditions and platelet hyperactivity}

In T2DM patients, other associated metabolic condition like obesity, dyslipidaemia and increased systemic inflammation may also contribute to increase platelet hyperactivity. Obesity is a common feature of patients with T2DM and can induce or exacerbate insulin resistance, which has significant consequences for platelet reactivity $[13,15,176]$. Furthermore, various metabolic abnormalities caused by obesity may leads to platelet hyperactivity. These abnormalities includes increased count and mean volume of platelets, which is associated with platelet reactivity and used as prognostic marker in various atherothrombotic conditions like acute coronary syndrome and stroke [176, 177]. Furthermore, increased cytosolic calcium concentration also enhances platelet reactivity [178]. In addition, high serum leptin concentration also leads to augmented platelet aggregability [179]. Overall, these abnormalities lead to increased platelet adhesion and activation [180, 181]. In a previous report involving subjects with central obesity, it was observed that weight loss induced by diet, reestablished sensitivity for $\mathrm{NO}$ and $\mathrm{PGI}_{2}$ and decrease platelet activation [182]. Moreover, obese patients were reported to have increased plasma CD40L and elevated levels of derived microparticles, which released in blood on platelet activation [176, 183-185]. Furthermore, subjects with higher BMI were detected to show impaired response to antiplatelet drugs like clopidogrel [186-188]. In obese women, it was observed that weight loss and insulin sensitization by pioglitazone lead to decreased levels of platelet activation markers [180, 183, 185].

T2DM patients are very susceptible to dyslipidaemia, comprised of increased triglycerides, elevated lowdensity lipoprotein cholesterol (LDL-C) and reduced high-density lipoprotein cholesterol (HDL-C) [13, 15]. Hypertriglyceridemia was reported to increase platelet activation, which is suggested to be mediated by apolipoprotein E, a content of triglyceride rich very low density lipoproteins (vLDL) particles [189-191]. Along with platelet activation, vLDL particles also impair fibrinolysis and disturbs coagulation cascade, thus resulting in atherothrombotic risk [191]. Furthermore, low HDL-C was observed to be associated with endothelial dysfunction in T2DM patients, leading to increased atherosclerosis [192]. Furthermore, it has been reported that in hypercholesterolemia patients, intravenous infusion of HDL reconstitution stabilizes endothelial function by increasing NO bioavailability in these patients [193]. In another report, it was observed that reconstituted HDL decrease platelet aggregation by inducing cholesterol efflux from platelets in diabetic patients [194].

Furthermore, the association of T2DM with increased systemic inflammation is well known. In T2DM, increased levels of inflammatory, coagulation and platelet activation markers (interleukin-6, sP-selectin, soluble CD40 ligand) and tissue factor were observed in comparison with healthy controls [195]. Furthermore, it was suggested that in diabetic patients inflammation increases expression of Fc $y$-RIIA receptors, which induces increased platelet activation in response to collagen $[196,197]$.

\section{Biomarkers of platelet hyperactivity in T2DM}

Various important markers of platelet activation includes sP-selectin, platelet factor 4 (PF4), $\beta$-thromboglubulin $(\beta-\mathrm{TG})$, glycoprotein $\mathrm{V}(\mathrm{CD} 42 \mathrm{~d})$, thromboxane B2 $\left(\mathrm{TXB}_{2}\right)$ and thrombospondin-1. P-selectin $(\mathrm{CD} 62 \mathrm{P})$ is a carbohydrate-binding lectins stored in platelets as well as endothelial cells. It is well known as a marker of platelet activation [198, 199]. Elevated levels of P-selectin are already reported in T1DM and T2DM patients without vascular complications [199-201]. Furthermore, in patients with peripheral artery disease (PAD), arterial hypertension CAD increased levels of P-selectin in plasma were associated with levels of $\beta$-TG but not with vWF and TM (markers of endothelium activation) [202204]. Pf4, a basic protein stored in platelet granules, is characterized with both anticoagulant and procoagulant properties. It also impairs migration and proliferation of endothelial cells [205]. Other important platelet protein $\beta$-TG is having $50 \%$ structural similarity with PF4 and act as a leukocyte chemoattractant. The estimation of $\beta$-TG in patients with normal renal function is considered as gold standard platelet activation detection. Increased levels of both of PF4 and $\beta$-TG were suggested as indicator of platelets degranulation in patients with both T1DM and T2DM without vascular complications [205]. Glycoprotein $\mathrm{V}$ is also expressed on platelets and megakaryocytes, and it binds to the complex GPIb/GPIX non-covalently and forms a receptor for both vWF and thrombin [206]. The other factor TXB2 is an inactive metabolite/product of thromboxane A2. As release of $\mathrm{TXA}_{2}$ increased in platelets, TXB2 levels were also elevated in platelets, liver, kidneys and lungs in correlation with increased $\beta$-TG and PF4 levels [207]. The other important marker thrombospondin-1 (TSP-1) is multifunctional glycoprotein mainly expressed on various types of cells including vascular smooth muscle cells, platelets and renal cells. After release of thrombospondin from platelets, TSP-1 binds to the surface of activated platelets. In a previous report, levels of TSP-1 were suggested to confirm renal 
damage and vascular impairment in patients with diabetic nephropathy [208].

Different platelet markers can be studied by using enzyme linked immune sorbent assay (ELISA) and Western blot. A standardized method like flow cytometry is widely used for estimation of platelet function. It has various advantages over other techniques as it requires small blood volume and is independent of platelet count [166, $209,210]$. It also permits expression analysis of various platelet activation markers as well as platelet receptors on distinct platelets. Furthermore, flow cytometry allows the quantification analysis of the associates that link platelet to the other blood cells [211-215].

Mean platelet volume (MPV), an important marker of platelet activation, gives idea about platelet size and activation of larger platelets represent more activity [216]. T2DM patients have been reported to have significantly higher MPV than controls, which is contributed to increased cytoplasmic alpha granule content, indicating impairment platelet-megakaryocyte system [216-218]. Hence, platelets can be an important entity to estimate vascular risk in T2DM [197, 198]. Furthermore, studies have observed independent association of MPV with diabetes and increased MPV indicates early diabetic thrombocytopathy in both type of DM without vascular complications $[205,219]$.

\section{Pharmacological influences on platelet hyperactivity and its biomarkers}

To reduce the vascular risk in the T2DM patients, studies have reported various therapeutic targets for platelet hyperactivity. As already mentioned above, platelet derived microparticles (PMP) are shown to be involved in the increased development of atherosclerotic plaque and formation of arterial thrombosis in diabetic patients. Undeniably, T2DM patients have platelets that are described by a hyperactive phenotype with increased activation, adhesion and aggregation that may attributable to development of atherothrombotic complications in these patients [220-222]. Therefore, elevated levels of specific microparticles can be used as important predictor of vascular injury and cardiovascular outcome, especially in patients with T2DM [223-226]. Furthermore, studies have indicated that PMP may transport platelet miRNA to a specific site in cardiovascular system, which may be used as novel biomarkers to improve diagnostics and treatment of vascular complications in diabetic patients [227]. Platelet-derived miRNAs i.e. miR-223 and miR126 have been shown to have highest association with CVD. miR-223 controls erythrocyte membrane protein band 4.1 like 3 (EPB41L3) gene, known to be associated with atherosclerosis. However, miR-126 regulates a VCAM-1 gene, known to be linked with endothelial dysfunction and atherosclerosis, indicating important role of platelet-derived miRNAs in regulation of key genes associated with atherosclerotic vascular complications [228, 229]. In another study, $N$-acetylcysteine was reported to provide protection against the risk of stroke by altering both systemic as well as vascular prothrombotic responses and correcting levels of antioxidants in T2DM patients [230].

Various antiplatelet and anticoagulant drugs have been suggested as novel therapeutic strategies to improve platelet function in T2DM [231-237]. Acetylsalicylic acid (aspirin), a cyclooxygenase (COX) inhibitor, has been known to have anti-inflammatory and antithrombotic properties from past several decades [233, 234]. In addition, aspirin is also used as a key molecule in antiplatelet treatment to decrease mortality due to myocardial infarction or stroke. However, in recent studies, low-dose aspirin was found to be associated with increased risk for gastrointestinal bleeding in T2DM patients in a primary prevention setting [238]. In addition, for long-term treatment or prevention of thromboembolic complications, use of oral anticoagulants is recommended [231]. From the past decades, vitamin $\mathrm{K}$ antagonists have been shown to have anticoagulant properties. The most important vitamin $\mathrm{K}$ antagonists that are currently in use are dicoumarol warfarin, phenprocoumon, acenocoumarol and rivaroxaban [239-242]. However, risk of a recurrent event among patients with venous thromboembolism has shown to be decreased with rivaroxaban at either a treatment dose $(20 \mathrm{mg})$ or a prophylactic dose $(10 \mathrm{mg})$ than with aspirin, without a significant increase in bleeding rates [243]. Furthermore, P2Y12 receptor antagonists such as clopidogrel, ticagrelor, prasugrel and cangrelor have been shown to chemically block the adenosine diphosphate (ADP) receptors (P2Y12) [231]. The overall effect on platelet includes reduction in platelet aggregation, conformational changes, emergence of pseudopodia and interaction with other cellular or plasma components involved in coagulation [244]. Furthermore, Glycoprotein IIb/IIIa inhibitors such as Abciximab, tirofiban and eptifibatide, inhibit the fibrinogen adhesion to activated platelet, blocking the formation of interplatelet bridges [231, 245, 246]. Furthermore, various anticoagulants have been shown to prevent the initiation as well as progression of coagulation and fibrin-clot formation/ propagation [237, 247, 248]. These drugs are being used for the prevention or treatment of atrial fibrillation and venous thromboembolism. These anticoagulants include unfractionated heparin, low molecular weight heparin. The recently introduced parenteral anti-factor Xa agents (fondaparinux) have widely replaced the unfractionated heparin [231]. 


\section{Conclusion}

Hyperglycemia and insulin resistance, the cardinal characteristics of T2DM, are responsible for affecting normal endothelial and platelet function, which are linked with the development of prothrombotic state in T2DM patients. This metabolic milieu increases the vascular risk in these patients, accounting for high mortality and morbidity rate observed in T2DM. Thus, understanding of mechanisms of endothelial and platelet dysfunction is emerging as a major issue in prevention and management of vascular complications in T2DM.

\begin{abstract}
Abbreviations
ADMA: asymmetrical dimethylarginine; AGEs: advanced glycation end products; $\beta$-TG: $\beta$-thromboglubulin; CAD: coronary artery disease; CD42d: glycoprotein v; CRP: c-reactive protein; DM: diabetes mellitus; ELISA: enzyme linked immune sorbent assay; eNOS: endothelial no synthase; EPCs: endothelial progenitor cells; ET-1: endothelin-1; FFAs: free fatty acids; FMD: flowmediated dilatation; GLP-1: glucagon-like peptide-1; GP: surface glycoproteins; HbA1C: glycated hemoglobin; HDL-C: high-density lipoprotein cholesterol; ICAM: inter-cellular adhesion molecule; IDF: International Diabetes Federation; IGF-1: insulin-like growth factor 1; IL-6: interleukin-6; IR: insulin receptor; IRS: insulin resistance substrate; JNK: C-jun n-terminal kinase; LDL-C: low-density lipoprotein cholesterol; MAPK: mitogen activated protein kinase; miRs: micrornas; MPV: mean platelet volume; NF-kB: nuclear factor-kb; NO: nitric oxide; oxLDL: oxidized low-density lipoprotein; PAD: peripheral artery disease; PAI-1: plasminogen activator inhibitor-1; PARP: poly (adp-ribose) polymerase; PET: positron emission tomography; PF4: platelet factor $4 ; \mathrm{PGI}_{2}$ : prostacyclin; $\mathrm{PI} 3 \mathrm{~K}$ : phosphatidylinositol-3-kinase; PKC: protein kinase c; PMP: platelet derived microparticles; RAGE: age receptors; RNS: reactive nitrogen species; ROS: reactive oxidative species; T2DM: type 2 diabetes mellitus; TNF-a: tumor necrosis factor- $a_{;} \mathrm{TXB}_{2}$ : thromboxane b2; VCAM: vascular adhesion molecule; VLDL: very low-density lipoprotein; VSMC: vascular smooth muscle cells; vWV: von willebrand factor; WHO: World Health Organization; Wnt: wingless-type family member.
\end{abstract}

\section{Authors' contributions}

All authors were responsible for drafting of this article and revising it critically for important intellectual content. All authors read and approved the final manuscript.

\section{Author details}

1 Department of Molecular Biology \& Biochemistry, Guru Nanak Dev University, Amritsar, Punjab, India. ${ }^{2}$ Department of Human Genetics, Guru Nanak Dev University, Amritsar, Punjab, India.

\section{Acknowledgements}

Not applicable.

\section{Competing interests}

The authors declare that they have no competing interests.

\section{Availability of data and materials}

Not applicable.

\section{Consent for publication}

Not applicable.

Ethics approval and consent to participate

Not applicable.

\section{Funding}

Not applicable.

\section{Publisher's Note}

Springer Nature remains neutral with regard to jurisdictional claims in published maps and institutional affiliations.

Received: 19 July 2018 Accepted: 20 August 2018

Published online: 31 August 2018

\section{References}

1. Patlak M. New weapons to combat an ancient disease: treating diabetes. FASEB J. 2002;16:1853.

2. Roglic G. WHO Global report on diabetes: a summary. Int J Noncommun Dis. 2016;1:3.

3. Atlas ID. In: 6th edn. Brussels: International Diabetes Federation; 2013; 2017. https://www.idf.org/component/attachments/attachment s.html. Accessed 10 July 2018.

4. Behnam-Rassouli M, Ghayour MB, Ghayour N. Microvascular complications of diabetes. J Biol Sci. 2010;10:411-23.

5. Haffner SM, Lehto S, Rönnemaa T, Pyörälä K, Laakso M. Mortality from coronary heart disease in subjects with type 2 diabetes and in nondiabetic subjects with and without prior myocardial infarction. N Engl J Med. 1998;339:229-34.

6. Beckman JA, Creager MA, Libby P. Diabetes and atherosclerosis: epidemiology, pathophysiology, and management. JAMA. 2002;287:2570-81.

7. Creager MA, Lüscher TF, Cosentino F, Beckman JA. Diabetes and vascular disease: pathophysiology, clinical consequences, and medical therapy: part I. Circulation. 2003;108:1527-32.

8. Nesto RW. Correlation between cardiovascular disease and diabetes mellitus: current concepts. Am J Med. 2004;116:11-22.

9. Kannel WB, D'Agostino RB, Wilson PW, Belanger AJ, Gagnon DR. Diabetes, fibrinogen, and risk of cardiovascular disease: the Framingham experience. Am Heart J. 1990;120:672-6.

10. Laakso M, Lehto S. Epidemiology of risk factors for cardiovascular disease in diabetes and impaired glucose tolerance. Atherosclerosis. 1998;137:65-73.

11. Dhananjayan R, Koundinya KS, Malati T, Kutala VK. Endothelial dysfunction in type 2 diabetes mellitus. IJCB. 2016;31:372-9.

12. Grant PJ. Diabetes mellitus as a prothrombotic condition. J Intern Med. 2007;262:157-72

13. Gaiz A, Mosawy S, Colson N, Singh I. Thrombotic and cardiovascular risks in type two diabetes; Role of platelet hyperactivity. Biomed Pharmacother. 2017;94:679-86.

14. Ferroni P, Basili S, Falco A, Davì G. Platelet activation in type 2 diabetes mellitus. J Thromb Haemost. 2004;2:1282-91.

15. Ferreiro JL, Gómez-Hospital JA, Angiolillo DJ. Platelet abnormalities in diabetes mellitus. Diab Vasc Dis Res. 2010;7:251-9.

16. Kakouros N, Rade JJ, Kourliouros A, Resar JR. Platelet function in patients with diabetes mellitus: from a theoretical to a practical perspective. Int J endocrinol. 2011;2011:742719.

17. Sumpio BE, Riley JT, Dardik A. Cells in focus: endothelial cell. Int J Biochem Cell Biol. 2002;34:1508-12.

18. Bonetti PO, Lerman LO, Lerman A. Endothelial dysfunction: a marker of atherosclerotic risk. Arterioscler Thromb Vasc Biol. 2003;23:168-75.

19. Félétou M, Vanhoutte PM. Endothelial dysfunction: a multifaceted disorder (the Wiggers Award Lecture). Am J Physiol Heart Circ Physiol. 2006;291:H985-1002.

20. Moncada S, Higgs EA. Nitric oxide and the vascular endothelium. Handb Exp Pharmacol. 2006;176:213-54.

21. Félétou $M$. The endothelium, part I: multiple functions of the endothelial cells-focus on endothelium-derived vasoactive mediators. In colloquium series on integrated systems physiology: from molecule to function. Morgan Claypool Life Sci. 2011;3:1-306.

22. Quyyumi AA. Endothelial function in health and disease: new insights into the genesis of cardiovascular disease. Am J Med. 1998;105:32-9.

23. Szmitko PE, Wang CH, Weisel RD, de Almeida JR, Anderson TJ, Verma S. New markers of inflammation and endothelial cell activation: part I. Circulation. 2003;108:1917-23. 
24. Just A, Whitten $C L$, Arendshorst WJ. Reactive oxygen species participate in acute renal vasoconstrictor responses induced by ETA and ETB receptors. Am J Physiol Renal Physiol. 2008;294:719-28.

25. Riccardo C, Stella B, Terri JA. Linking diabetes and atherosclerosis. Expert Rev Endocrinol Metab. 2009;4:603-24.

26. Ceriello A. Point: postprandial glucose levels are a clinically important treatment target. Diabetes Care. 2010;33:1905-7.

27. Grassi D, Desideri G, Necozione S. Protective effects of flavanol-rich dark chocolate on endothelial function and wave reflection during acute hyperglycemia. Hypertension. 2012;60:827-32.

28. Poredos P, Spirkoska A, Lezaic L, Mijovski MB, Jezovnik MK. Patients with an inflamed atherosclerotic plaque have increased levels of circulating inflammatory markers. J Atheroscler Thromb. 2017;24:39-46.

29. Skyler JS, Bergenstal R, Bonow RO, et al. Intensive glycemic control and the prevention of cardiovascular events: implications of the ACCORD, ADVANCE, and VA diabetes trials: a position statement of the American Diabetes Association and a scientific statement of the American College of Cardiology Foundationand the American Heart Association. Circulation. 2009;119:351-7.

30. Brownlee M. The pathobiology of diabetes complications: a unifying mechanism. Diabetes. 2005;54:1615-25.

31. Kuroki M, Voest EE, Amano S, et al. Reactive oxygen intermediates increase vascular endothelial growth factor expression in vitro and in vivo. J Clin Invest. 1996;98:1667-75.

32. Liochev SI, Fridovich I. The role of $\mathrm{O} 2-$. in the production of $\mathrm{HO}$ : in vitro and in vivo. Free Radic Biol Med. 1994;6:29-33.

33. Tesfamariam B, Cohen RA. Free radicals mediate endothelial cell dysfunction caused by elevated glucose. Am J Physiol. 1992;263:321-6.

34. Vincent AM, Russell JW, Low P, Feldman E. Oxidative stress in the pathogenesis of diabetic neuropathy. Endocr Rev. 2004;25:612-28.

35. Park K, Gross M, Lee DH, Holvoet P, Himes JH, Shikany JM, Jacobs DR $\mathrm{Jr}$. Oxidative stress and insulin resistance: the coronary artery risk development in young adults study. Diabetes Care. 2009;32:1302-7.

36. Holvoet $P$, Lee DH, Steffes M, Gross M, Jacobs DR Jr. Association between circulating oxidized low-density lipoprotein and incidence of the metabolic syndrome. JAMA. 2008;299:2287-93.

37. II'yasova D, Spasojevic I, Base K, Zhang H, Wang F, Young SP, Millington DS, D'Agostino RB Jr, Wagenknecht LE. Urinary F2-isoprostanes as a biomarker of reduced risk of type 2 diabetes. Diabetes Care. 2012:35:173-4.

38. Meigs JB, Larson MG, Fox CS, Keaney JF Jr, Vasan RS, Benjamin EJ. Association of oxidative stress, insulin resistance, and diabetes risk phenotypes: the Framingham Offspring Study. Diabetes Care. 2007;30(2929-35):155.

39. Odegaard AO, Jacobs DR, Sanchez OA, et al. Oxidative stress, inflammation, endothelial dysfunction and incidence of type 2 diabetes. Cardiovasc Diabetol. 2016;15:51.

40. Brownlee M. Biochemistry and molecular cell biology of diabetic complications. Nature. 2001;13:813-20.

41. D'Souza A, Hussain M, Howarth FC, Woods NM, Bidasee K, Singh J. Pathogenesis and pathophysiology of accelerated atherosclerosis in the diabetic heart. Mol Cell Biochem. 2009;331:89-116.

42. Potenza MA, Gagliardi S, Nacci C, Carratu MR, Montagnani M. Endothelial dysfunction in diabetes: from mechanisms to therapeutic targets. Curr Med Chem. 2009;16:94-112.

43. Schmidt AM, Du Yan S, Wautier JL, Stern D. Activation of receptor for advanced glycation end products: a mechanism for chronic vascular dysfunction in diabetic vasculopathy and atherosclerosis. Circ Res. 1999;84:489-97.

44. Wautier MP, Chappey O, Corda S, Stern DM, Schmidt AM, Wautier JL. Activation of NADPH oxidase by AGE links oxidant stress to altered gene expression via RAGE. Am J Physiol Endocrinol Metab. 2001;280:685-94.

45. Chavakis T, Bierhaus A, Nawroth PP. RAGE (receptor for advanced glycation end products): a central player in the inflammatory response. Microbes Infect. 2004:6:1219-25.

46. Chakravarthy U, Hayes RG, Stitt AW, McAuley E, Archer DB. Constitutive nitric oxide synthase expression in retinal vascular endothelial cells is suppressed by high glucose and advanced glycation end products. Diabetes. 1998;47:945-52.
47. Quehenberger A, Bierhaus P, Fasching C, et al. Endothelin 1 transcription is controlled by nuclear factor-kappaB in AGE-stimulated cultured endothelial cells. Diabetes. 2000:49:1561-70.

48. Xu B, Chibber R, Ruggiero D, Kohner E, Ritter J, Ferro A. Impairment of vascular endothelial nitric oxide synthase activity by advanced glycation end products. FASEB J. 2003;17:1289-91.

49. Sena CM, Pereira AM, Seiça R. Endothelial dysfunction-a major mediator of diabetic vascular disease. Acta Mol Basis Dis Biochimica et Biophysica Acta Mol Basis Dis. 2013;1832:2216-31.

50. Casanova F, Adingupu DD, Adams F, et al. The impact of cardiovascular co-morbidities and duration of diabetes on the association between microvascular function and glycaemic control. Cardiovasc Diabetol. 2017:16:114.

51. Chen X, Duong MN, Psaltis PJ, et al. High-density lipoproteins attenuate high glucose-impaired endothelial cell signaling and functions: potential implications for improved vascular repair in diabetes. Cardiovasc Diabetol. 2017;16:121

52. Ebtehaj S, Gruppen EG, Parvizi M, et al. The anti-inflammatory function of HDL is impaired in type 2 diabetes: role of hyperglycemia, paraoxonase-1 and low grade inflammation. Cardiovasc Diabetol. 2017;16:132.

53. Costantino S, Paneni F, Battista R, et al. Impact of glycemic variability on chromatin remodeling, oxidative stress, and endothelial dysfunction in patients with type 2 diabetes and with target $\mathrm{HbA} 1 \mathrm{c}$ levels. Diabetes. 2017:66:2472-82.

54. Widlansky ME, Jensen DM, Wang J, et al. miR-29 contributes to normal endothelial function and can restore it in cardiometabolic disorders. EMBO Mol Med. 2018;10:e8046.

55. Reaven GM. Role of insulin resistance in human disease. Diabetes. 1998;37:1595-607.

56. Saltiel AR, Kahn CR. Insulin signalling and the regulation of glucose and lipid metabolism. Nature. 2001:414:799-806.

57. Paneni F, Beckman JA, Creager MA, Cosentino F. Diabetes and vascular disease: pathophysiology, clinical consequences, and medical therapy: part I. Eur Heart J. 2013;34:2436-46.

58. Poirier P, Giles TD, Bray GA, et al. Obesity and cardiovascular disease: pathophysiology, evaluation, and effect of weight loss: an update of the 1997 American Heart Association Scientific Statement on Obesity and Heart Disease from the Obesity Committee of the Council on Nutrition, Physical Activity, and Metabolism. Circulation. 2006;113:898-918.

59. Baron AD, Laakso M, Brechtel G, Edelman SV. Mechanism of insulin resistance in insulin dependent diabetes mellitus: a major role for reduced skeletal muscle blood flow. J Clin Endocrinol Metab. 1991;73:637-43.

60. Natali A, Taddei S, Galvan AQ, et al. Insulin sensitivity, vascular reactivity, and clamp-induced vasodilatation in essential hypertension. Circulation. 1997;96:849-55.

61. Kim JA, Montagnani M, Koh KK, Quon MJ. Reciprocal relationships between insulin resistance and endothelial dysfunction: molecular and pathophysiological mechanisms. Circulation. 2006;113:1888-904.

62. Muniyappa R, Sowers JR. Roles of insulin resistance in endothelial dysfunction. Rev Endocr Metab Disord. 2013;14:5-12.

63. Inoguchi T, Li P, Umeda F, et al. High glucose level and free fatty acid stimulate reactive oxygen species production through protein kinase C-dependent activation of $\mathrm{NAD}(\mathrm{P}) \mathrm{H}$ oxidase in cultured vascular cells. Diabetes. 2000:49:1939-45.

64. Natali E, Toschi S, Baldeweg D, et al. Clustering of insulin resistance with vascular dysfunction and low-grade inflammation in type 2 diabetes. Diabetes. 2006:55:1133-40.

65. Emoto M, Nishizawa Y, Maekawa K, et al. Homeostasis model assessment as a clinical index of insulin resistance in type 2 diabetic patients treated with sulfonylureas. Diabetes Care. 1999;22:818-22.

66. Bonora $\mathrm{E}$, Targher $\mathrm{G}$, Alberiche $\mathrm{M}$, et al. Homeostasis model assessment closely mirrors the glucose clamp technique in the assessment of insulin sensitivity. Diabetes Care. 2000;23:57-63.

67. Fukushima M, Taniguchi A, Sakai M, et al. Homeostasis model assessment as a clinical index of insulin resistance: comparison with the minimal model analysis (Letter). Diabetes Care. 1999;22:1911.

68. Westergren HU, Svedlund S, Momo RA, et al. Insulin resistance, endothelial function, angiogenic factors and clinical outcome in nondiabetic patients with chest pain without myocardial perfusion defects. Cardiovasc Diabetol. 2016;15:36. 
69. Wang F, Chen FF, Shang YY, et al. Insulin resistance adipocyte-derived exosomes aggravate atherosclerosis by increasing vasa vasorum angiogenesis in diabetic ApoE-/-mice. Int J Cardiol. 2018;265:181-7.

70. Dresner A, Laurent D, Marcucci M, et al. Effects of free fatty acids on glucose transport and IRS-1-associated phosphatidylinositol 3-kinase activity. J Clin Invest. 1999;103:253-9.

71. Kawashima S, Yokoyama M. Dysfunction of endothelial nitric oxide synthase and atherosclerosis. Arterioscler Thromb Vasc Biol. 2004;24:998-1005.

72. Steinberg HO, Tarshoby M, Monestel R, et al. Elevated circulating free fatty acid levels impair endothelium-dependent vasodilation. J Clin Invest. 1997;100:1230-9.

73. Gao Z, Zhang X, Zuberi A, Hwang D, Quon MJ, Lefevre M, Ye J. Inhibition of insulin sensitivity by free fatty acids requires activation of multiple serine kinases in 3T3-L1 adipocytes. Mol Endocrinol. 2004;18:2024-34.

74. Boden G, She P, Mozzoli M, et al. Free fatty acids produce insulin resistance and activate the proinflammatory nuclear factor-kappaB pathway in rat liver. Diabetes. 2005;54:3458-65.

75. Jové M, Planavila A, Sánchez RM, Merlos M, Laguna JC, Vázquez-Carrera M. Palmitate induces tumor necrosis factor-alpha expression in $\mathrm{C} 2 \mathrm{C} 12$ skeletal muscle cells by a mechanism involving protein kinase $\mathrm{C}$ and nuclear factor-kappaB activation. Endocrinology. 2006;147:552-61.

76. Kim F, Tysseling KA, Rice J, et al. Free fatty acid impairment of nitric oxide production in endothelial cells is mediated by IKK beta. Arterioscler Thromb Vasc Biol. 2005;25:989-94.

77. Naruse K, Rask-Madsen C, Takahara N, et al. Activation of vascular protein kinase $C-\beta$ inhibits Akt-dependent endothelial nitric oxide synthase function in obesity-associated insulin resistance. Diabetes. 2006;55:691-8.

78. Wang $X L$, Zhang $L$, Youker $K$, et al. Free fatty acids inhibit insulin signaling-stimulated endothelial nitric oxide synthase activation through upregulating PTEN or inhibiting Akt kinase. Diabetes. 2006;55:2301-10.

79. Zhang X, McGeoch SC, Johnstone AM, et al. Platelet-derived microparticle count and surface molecule expression differ between subjects with and without type 2 diabetes, independently of obesity status. J Thromb Thrombolysis. 2014;37:455-63.

80. Capurso C, Capurso A. From excess adiposity to insulin resistance: the role of free fatty acids. Vasc Pharmacol. 2012;57:91-7.

81. Du X, Edelstein D, Obici S, Higham N, Zou MH, Brownlee M. Insulin resistance reduces arterial prostacylcin synthase and eNOS activities by increasing endothelial fatty acid oxidation. J Clin Invest. 2006;116:1071-80.

82. Giacco F, Brownlee M. Oxidative stress and diabetic complications. Circ Res. 2010;107:1058-70.

83. Deanfield J, Donald A, Ferri C. Endothelial function and dysfunction. Part I: methodological issues for assessment in the different vascular beds: a statement by the Working Group on Endothelin and Endothelial Factors of the European Society of Hypertension. J Hypertens. 2005;23:7-17.

84. Barac A, Campia U, Panza JA. Methods for evaluating endothelial function in humans. Hypertension. 2007;49:748-60.

85. Hamburg NM, Keyes MJ, Larson MG, et al. Cross-sectional relations of digital vascular function to cardiovascular risk factors in the Framingham Heart Study. Circulation. 2008;117:2467-74.

86. Prior JO, Quinones MJ, Hernandez-Pampaloni M, et al. Coronary circulatory dysfunction in insulin resistance, impaired glucose tolerance, and type 2 diabetes mellitus. Circulation. 2005;111:2291-8.

87. Ketel IJ, Stehouwer CD, Serne EH, et al. Obese but not normal-weight women with polycystic ovary syndrome are characterized by metabolic and microvascular insulin resistance. J Clin Endocrinol Metab. 2008:93:3365-72.

88. Muniyappa R, Hall G, Kolodziej TL, Karne RJ, Crandon SK, Quon MJ Cocoa consumption for 2 wk enhances insulin-mediated vasodilatation without improving blood pressure or insulin resistance in essential hypertension. Am J Clin Nutr. 2008;88:1685-96.

89. Huang Z, Chen C, Li S, Kong F, Shan P, Huang W. Serum markers of endothelial dysfunction and inflammation increase in hypertension with prediabetes mellitus. Genet Test Mol Biomarkers. 2016;20:322-7.

90. Idris-Khodja N, Ouerd S, Mian MO, et al. Endothelin-1 overexpression exaggerates diabetes-induced endothelial dysfunction by altering oxidative stress. Am J Hypertens. 2016;29:1245-51.
91. Lee J, Lee S, Zhang H, Hill MA, Zhang C, Park Y. Interaction of IL-6 and TNF-a contributes to endothelial dysfunction in type 2 diabetic mouse hearts. PLoS ONE. 2017;12:e0187189.

92. Halleskog C, Schulte G. WNT-3A and WNT-5A counteract lipopolysaccharide-induced pro-inflammatory changes in mouse primary microglia. J Neurochem. 2013;125:803-8.

93. Bhatt PM, Malgor R. Wnt5a: a player in the pathogenesis of atherosclerosis and other inflammatory disorders. Atherosclerosis. 2014;237:155-62.

94. Bretón-Romero R, Feng B, Holbrook M. Endothelial dysfunction in human diabetes is mediated by Wnt5a-JNK signaling. Arterioscler Thromb Vasc Biol. 2016;36:561-9.

95. Avogaro A, Albiero M, Menegazzo L, de Kreutzenberg S, Fadini GP. Endothelial dysfunction in diabetes: the role of reparatory mechanisms. Diabetes Care. 2011;34:285-90.

96. Abbas RF, Mohammed MA, Attia MS. Study of circulating endothelial progenitor cells and endothelial dysfunction in type 2 diabetes mellitus patients. Clin Med Diagn. 2016;6:62-9.

97. Santi D, Giannetta E, Isidori AM, Vitale C, Aversa A, Simoni M. Therapy of endocrine disease: effects of chronic use of phosphodiesterase inhibitors on endothelial markers in type 2 diabetes mellitus: a meta-analysis. Eur J Endocrinol. 2015;172:103-14.

98. Fetterman JL, Holbrook M, Flint N, et al. Restoration of autophagy in endothelial cells from patients with diabetes mellitus improves nitric oxide signaling. Atherosclerosis. 2016;247:207-17.

99. Kaesemeyer WH. Endothelial nitric oxide synthase is a site of superoxide synthesis in endothelial cells treated with glyceryl trinitrate. $\mathrm{Br} J \mathrm{Phar}$ macol. 2000;131:1019-23.

100. Morris SM Jr. Enzymes of arginine metabolism. Int J Nutr. 2004;134:2743-7.

101. Kondo K, Morino K, Nishio Y, et al. Fiber-rich diet with brown rice improves endothelial function in type 2 diabetes mellitus: a randomized controlled trial. PLOS ONE. 2017;12:e0179869.

102. Sharma A, Rizky L, Stefanovic N, et al. The nuclear factor (erythroidderived 2)-like 2 (Nrf2) activator dh404 protects against diabetesinduced endothelial dysfunction. Cardiovasc Diabetol. 2017;16:33.

103. Chen XL, Dodd G, Thomas S, Zhang X, Wasserman MA, Rovin BH, Kunsch C. Activation of nrf2/are pathway protects endothelial cells from oxidant injury and inhibits inflammatory gene expression. Am J Physiol Heart Circ Physiol. 2006;290:1862-70.

104. Dreger H, Westphal K, Wilck N, Baumann G, Stangl V, Stangl K, Meiners S. Protection of vascular cells from oxidative stress by proteasome inhibition depends on nrf2. Cardiovasc Res. 2010;85:395-403.

105. Itoh K, Tong Kl, Yamamoto M. Molecular mechanism activating nrf2keap1 pathway in regulation of adaptive response to electrophiles. Free Radic Biol Med. 2004;36:1208-13.

106. Jung KA, Kwak MK. The nrf2 system as a potential target for the development of indirect antioxidants. Molecules. 2010;15:7266-91.

107. Tan SM, de Haan JB. Combating oxidative stress in diabetic complications with nrf2 activators: how much is too much? Redox Rep. 2014;19:107-17.

108. Shatanawi A, Momani MS. Plasma arginase activity is elevated in type 2 diabetic patients. Biomed Res. 2017:28:4102-6.

109. Salim HM, Fukuda D, Yagi S, Soeki T, Shimabukuro M, Sata M. Glycemic control with ipragliflozin, a novel selective SGLT2 inhibitor, ameliorated endothelial dysfunction in streptozotocin-induced diabetic mouse. Front Cardiovasc Med. 2016:3:1-9.

110. Zhang M, Zhang L, Wu B, Song H, An Z, Li S. Dapagliflozin treatment for type 2 diabetes: a systematic review and meta-analysis of randomized controlled trials. Diabetes Metab Res Rev. 2014;30:204-21.

111. Scheerer MF, Rist R, Proske O, Meng A, Kostev K. Changes in HbA1C, body weight, and systolic blood pressure in type 2 diabetes patients initiating dapagliflozin therapy: a primary care database study. Diabetes Metab Syndr Obes Targets Ther. 2016:9:337-45.

112. Ott C, Jumar A, Striepe K, et al. A randomised study of the impact of the SGLT2 inhibitor dapagliflozin on microvascular and macrovascular circulation. Cardiovasc Diabetol. 2017;16:26.

113. Solini A, Giannini L, Seghieri M, et al. Dapagliflozin acutely improves endothelial dysfunction, reduces aortic stiffness and renal resistive index in type 2 diabetic patients: a pilot study. Cardiovasc Diabetol. 2017;16:138. 
114. Shigiyama F, Kumashiro N, Miyagi M, et al. Effectiveness of dapagliflozin on vascular endothelial function and glycemic control in patients with early-stage type 2 diabetes mellitus: DEFENCE study. Cardiovasc Diabetol. 2017;16:84.

115. Jax T, Stirban A, Terjung A, et al. A randomised, active- and placebocontrolled, three-period crossover trial to investigate short-term effects of the dipeptidyl peptidase-4 inhibitor linagliptin on macro- and microvascular endothelial function in type 2 diabetes. Cardiovasc Diabetol. 2017;16:13.

116. Koyama T, Tanaka A, Yoshida H, et al. Comparison of the effects of linagliptin and voglibose on endothelial function in patients with type 2 diabetes and coronary artery disease: a prospective, randomized, pilot study (EFFORT). Heart Vessels. 2018. https://doi.org/10.1007/s0038 0-018-1136-2.

117. Krzyzanowska K, Mittermayer F, Shnawa N, Hofer M, Schnabler J, Etmuller Y, Kapiotis S, Wolzt M, Schernthaner G. Asymmetrical dimethylarginine is related to renal function, chronic inflammation and macroangiopathy in patients with Type 2 diabetes and albuminuria. Diabet Med. 2007; $24: 81-6$

118. Celik M, Cerrah S, Arabul M, Akalin A. Relation of asymmetric dimethylarginine levels to macrovascular disease and inflammation markers in type 2 diabetic patients. J Diabetes Res. 2014;2014:139215.

119. Willeit P, Freitag DF, Laukkanen JA, Chowdhury S, Gobin R, Mayr M, Di Angelantonio E, Chowdhury R. Asymmetric dimethylarginine and cardiovascular risk: systematic review and meta-analysis of 22 prospective studies. J Am Heart Assoc. 2015;4:e001833.

120. Schlesinger S, Sonntag SR, Lieb W, Maas R. Asymmetric and symmetric dimethylarginine as risk markers for total mortality and cardiovascular outcomes: a systematic review and meta-analysis of prospective studies. PLoS ONE. 2016;11:e0165811.

121. Kim KM, Jung KY, Yun HM, et al. Effect of rosuvastatin on fasting and postprandial endothelial biomarker levels and microvascular reactivity in patients with type 2 diabetes and dyslipidemia: a preliminary report. Cardiovasc Diabetol. 2017;16:146.

122. Nyström T, Gutniak MK, Zhang Q, et al. Effects of glucagon-like peptide-1 on endothelial function in type 2 diabetes patients with stable coronary artery disease. Am J Physiol Endocrinol Metab. 2014:287:1209-15.

123. Torimoto K, Okada Y, Mori H. Effects of exenatide on postprandial vascular endothelial dysfunction in type 2 diabetes mellitus. Cardiovasc Diabetol. 2015;14:25-32.

124. Ban K, Noyan-Ashraf MH, Hoefer J, Bolz SS, Drucker DJ, Husain M. Cardioprotective and vasodilatory actions of glucagon-like peptide 1 receptor are mediated through both glucagon-like peptide 1 receptordependent and -independent pathways. Circulation. 2008;117:2340-50.

125. Oyama J, Higashi Y, Node K. Do incretins improve endothelial function? Cardiovasc Diabetol. 2014;13:21.

126. Pankow JS, Decker PA, Berardi C, et al. Circulating cellular adhesion molecules and risk of diabetes: the multi-ethnic study of atherosclerosis (MESA). Diabet Med. 2016;33:985-91.

127. Davi G, Ferroni P. Microparticles in type 2 diabetes mellitus. J Thromb Haemost. 2005;3:1166-7.

128. Kaur R, Singh J, Kapoor R, Kaur M. Association of SELP polymorphisms with soluble P-selectin levels and vascular risk in patients with type 2 diabetes mellitus: a case-control study. Biochem Genet. 2018. https:// doi.org/10.1007/s10528-018-9881-6.

129. Tramontano AF, Lyubarova R, Tsiakos J, Palaia T, Deleon JR, Ragolia L. Circulating endothelial microparticles in diabetes mellitus. Mediators Inflamm. 2010;2010:250476.

130. Santilli F, Marchisio M, Lanuti P, Boccatonda A, Miscia S, Davì G. Microparticles as new markers of cardiovascular risk in diabetes and beyond. Thromb Haemost. 2016;116:220-34.

131. Shantikumar S, Caporali A, Emanueli C. Role of microRNAs in diabetes and its cardiovascular complications. Cardiovasc Res. 2012;93:583-93.

132. Zampetaki A, Mayr M. MicroRNAs in vascular and metabolic disease. Circ Res. 2012:110:508-22.

133. Karolina DS, Armugam A, Tavintharan S, et al. MicroRNA 144 impairs insulin signaling by inhibiting the expression of insulin receptor substrate 1 in type 2 diabetes mellitus. PLoS ONE. 2011;6:e22839.

134. Dehwah MA, Xu A, Huang Q. MicroRNAs and type 2 diabetes/obesity. J Genet Genomics. 2012;39:11-8.
135. Caporali A, Meloni M, Vollenkle C, et al. Deregulation of microRNA-503 contributes to diabetes mellitus-induced impairment of endothelial function and reparative angiogenesis after limb ischemia. Circulation. 2011;123:282-91.

136. Sheng T, Yang K. Adiponectin and its association with insulin resistance and type 2 diabetes. J Genet Genom. 2008;35:321-6.

137. Kadowaki T, Yamauchi T, Kubota N, Hara K, Ueki K, Tobe K. Adiponectin and adiponectin receptors in insulin resistance, diabetes, and the metabolic syndrome. J Clin Invest. 2006;116:1784-92.

138. Fukuda S, Hirata A, Nishizawa H, et al. Systemic arteriosclerosis and eating behavior in Japanese type 2 diabetic patients with visceral fat accumulation. Cardiovasc Diabetol. 2015;14(1):8.

139. Hartge MM, Kintscher U, Unger T. Endothelial dysfunction and its role in diabetic vascular disease. Endocrinol Metab Clin North Am. 2006;35:551-60.

140. Hug C, Wang J, Ahmad NS, Bogan JS, Tsao TS, Lodish HF. T-cadherin is a receptor for hexameric and high-molecular-weight forms of Acrp30/ adiponectin. Proc Natl Acad Sci USA. 2004;101:10308-13.

141. Kostopoulos CG, Spiroglou SG, Varakis JN, Apostolakis E, Papadaki HH. Adiponectin/T-cadherin and apelin/APJ expression in human arteries and periadventitial fat: implication of local adipokine signaling in atherosclerosis? Cardiovasc Pathol. 2014;23:131-8.

142. Parker-Duffen JL, Nakamura K, Silver M, Kikuchi R, Tigges U, Yoshida S, Denzel MS, Ranscht B, Walsh K. T-cadherin is essential for adiponectinmediated revascularization. J Biol Chem. 2013;288:24886-97.

143. Wang H, Tao L, Ambrosio A, et al. T-cadherin deficiency increases vascular vulnerability in T2DM through impaired NO bioactivity. Cardiovasc Diabetol. 2017;16:12.

144. Ribatti D, Crivellato E. Giulio Bizzozero and the discovery of platelets. Leuk Res. 2007;31:1339-41. https://doi.org/10.1016/j.leukr es.2007.02.008

145. Stenberg PE. A platelet alpha-granule membrane protein (GMP-140) is expressed on the plasma membrane after activation. J Cell Biol. 1985;101:880-6.

146. Kestin AS, Ellis PA, Barnard MR, Errichetti A, Rosner BA, Michelson AD. Effect of strenuous exercise on platelet activation state and reactivity. Circulation. 1993;88:1502-11.

147. Gryglewski RJ. Mediators produced by the endothelial cell. Hypertension. 1988;12:530-48.

148. Vinik Al, Erbas T, Park TS, Nolan R, Pittenger GL. Platelet dysfunction in type 2 diabetes. Diabetes Care. 2001;24:1476-85.

149. Takada Y, Urano T, Watanabe I, Taminato A, Yoshimi T, Takada A. Changes in fibrinolytic parameters in male patients with type 2 (non-insulindependent) diabetes mellitus. Thromb Res. 1993;71:405-15.

150. Osende Jl, Badimon JJ, Fuster V, et al. Blood thrombogenicity in type 2 diabetes mellitus patients is associated with glycemic control. J Am Coll Cardiol. 2001:38:1307-12.

151. Stratmann B, Tschoepe D. Pathobiology and cell interactions of platelets in diabetes. Diab Vasc Dis Res. 2005:2:16-23.

152. Lefebvre PJ, Scheen AJ. Glucose metabolism and the postprandial state. Eur J Clin Invest. 1999:29:1-6.

153. Tominaga M, Eguchi $H$, Manaka H, Igarashi K, Kato TA, Sekikawa A. Impaired glucose tolerance is a risk factor for cardiovascular disease, but not impaired fasting glucose. The Funagata Diabetes Study. Diabetes Care. 1999:22:920-4.

154. Winocour PD, Watala C, Perry DW, Kinlough-Rathbone RL. Decreased platelet membrane fluidity due to glycation or acetylation of membrane proteins. Thromb Haemost. 1992;68:577-82.

155. Watala C, Golański J, Boncler MA, Pietrucha T, Gwoździński K. Membrane lipid fluidity of blood platelets: a common denominator that underlies the opposing actions of various agents that affect platelet activation in whole blood. Platelets. 1998;9:315-27.

156. Keating FK, Sobel BE, Schneider DJ. Effects of increased concentrations of glucose on platelet reactivity in healthy subjects and in patients with and without diabetes mellitus. Am J Cardiol. 2003;92:1362-5.

157. Assert R, Scherk G, Bumbure A, Pirags V, Schatz H, Pfeiffer AF. Regulation of protein kinase $C$ by short term hyperglycaemia in human platelets in vivo and in vitro. Diabetologia. 2001;44:188-95.

158. Ferretti G, Rabini RA, Bacchetti T, et al. Glycated low-density lipoproteins modify platelet properties: a compositional and functional study. J Clin Endocrinol Metab. 2002:87:2180-4. 
159. Kessler L, Wiesel ML, Attali P, Mossard JM, Cazenave JP, Pinget M. Von Willebrand factor in diabetic angiopathy. Diabetes Metab. 1998;24:327-36.

160. Boden G, Rao AK. Effects of hyperglycemia and hyperinsulinemia on the tissue factor pathway of blood coagulation. Curr Diab Rep. 2007;7:223-7.

161. Eibl N, Krugluger W, Streit G, Schrattbauer K, Hopmeier P, Schernthaner G. Improved metabolic control decreases platelet activation markers in patients with type-2 diabetes. Eur J Clin Invest. 2004:34:205-9.

162. Ghoshal K, Bhattacharyya M. Overview of platelet physiology: its hemostatic and nonhemostatic role in disease pathogenesis. Sci World J. 2014:2014:1-16.

163. Yngen M, Östenson CG, Li N, Hjemdahl P, Wallen NH. Acute hyperglycemia increases soluble P-selectin in male patients with mild diabetes mellitus. Blood Coagul Fibrinolysis. 2001;12:109-16.

164. Vaidyula VR, Rao AK, Mozzoli M, Homko C, Cheung P, Boden G. Effects of hyperglycemia and hyperinsulinemia on circulating tissue factor procoagulant activity and platelet CD40 ligand. Diabetes. 2006:55:202-8.

165. Undas A, Wiek I, Stępień E, Zmudka K, Tracz W. Hyperglycemia is associated with enhanced thrombin formation, platelet activation and fibrin clot resistance to lysis in patients with acute coronary syndrome. Diabetes Care. 2008;31:1590-5.

166. Randriamboavonjy V, Fleming I. Insulin, insulin resistance, and platelet signaling in diabetes. Diabetes Care. 2009;32:528-30.

167. Falcon C, Pfliegler G, Deckmyn H, Vermylen J. The platelet insulin receptor: detection, partial characterization, and search for a function. Biochem Biophys Res Commun. 1998;157:1190-6.

168. Hwang DL, Yen CF, Nadler JL. Insulin increases intracellular magnesium transport in human platelets. J Clin Endocrinol Metab. 1993;76:549-53.

169. Trovati M, Anfossi G, Massucco P, et al. Insulin stimulates nitric oxide synthesis in human platelets and through nitric oxide, increases platelet concentrations of both guanosine-3_5_-cyclic monophosphate and adenosine-3',5'-cyclic monophosphate". Diabetes. 1997:46:742-9.

170. Ferreira IA, Eybrechts KL, Mocking Al, Kroner C, Akkerman JW. IRS-1 mediates inhibition of $\mathrm{Ca} 2+$ mobilization by insulin via the inhibitory G-protein Gi. J Biol Chem. 2004:279:3254-64.

171. Hunter RW, Hers I. Insulin/IGF-1 hybrid receptor expression on human platelets: consequences for the effect of insulin on platelet function. $J$ Thromb Haemost. 2009;7:2123-30.

172. Hajek AS, Joist JH. Platelet insulin receptor. Methods Enzymol. 1992;215:398-403.

173. Hers I. Insulin-like growth factor-1 potentiates platelet activation via the IRS/PI3Ka pathway. Blood. 2007;1 10:4243-52.

174. Westerbacka J, Yki-Järvinen H, Turpeinen A, et al. Inhibition of plateletcollagen interaction: an in vivo action of insulin abolished by insulin resistance in obesity. Arterioscler Thromb Vasc Biol. 2002;22:167-72.

175. Singh I, Mok M, Christensen AM, Turner AH, Hawley JA. The effects of polyphenols in olive leaves on platelet function. Nutr Metab Cardiovasc Dis. 2008;18:127-32.

176. Muscari A, De Pascalis S, Cenni A, et al. Determinants of mean platelet volume (MPV) in an elderly population: relevance of body fat, blood glucose and ischaemic electrocardiographic changes. Thromb Haemost. 2008;99:1079-84.

177. Vizioli L, Muscari S, Muscari A. The relationship of mean platelet volume with the risk and prognosis of cardiovascular diseases. Int J Clin Pract. 2009:63:1509-15.

178. Scherrer U, Nussberger J, Torriani S, et al. Effect of weight reduction in moderately overweight patients on recorded ambulatory blood pressure and free cytosolic platelet calcium. Circulation. 1991;83:552-8.

179. Sugiyama C, Ishizawa M, Kajita K, et al. Platelet aggregation in obese and diabetic subjects: association with leptin level. Platelets. 2007:18:128-34.

180. Murakami T, Horigome H, Tanaka K, et al. Impact of weight reduction on production of platelet-derived microparticles and fibrinolytic parameters in obesity. Thromb Res. 2007;119:45-53.

181. Schneider DJ, Hardison RM, Lopes N, et al. Association between increased platelet P-selectin expression and obesity in patients with type 2 diabetes: a BARI 2D (Bypass Angioplasty Revascularization Investigation 2 Diabetes) substudy. Diabetes Care. 2009;32:944-9.
182. Russo I, Traversa M, Bonomo K, et al. In central obesity, weight loss restores platelet sensitivity to nitric oxide and prostacyclin. Obesity (Silver Spring). 2010;18:788-97.

183. Kahn BB, Flier JS. Obesity and insulin resistance. J Clin Invest. 2000:106:473-81.

184. Davì G, Guagnano MT, Ciabattoni G. Platelet activation in obese women: role of inflammation and oxidant stress. JAMA. 2002;288:2008-14.

185. Basili S, Pacini G, Guagnano MT, et al. Insulin resistance as a determinant of platelet activation in obese women. J Am Coll Cardiol. 2006;48:2531-8.

186. Angiolillo DJ, Fernández-Ortiz A, Bernardo E, et al. Platelet aggregation according to body mass index in patients undergoing coronary stenting: should clopidogrel loading-dose be weight adjusted? J Invasive Cardiol. 2004;16:169-74.

187. Sibbing D, von Beckerath O, Schömig A, Kastrati A, von Beckerath N Impact of body mass index on platelet aggregation after administration of a high loading dose of $600 \mathrm{mg}$ of clopidogrel before percutaneous coronary intervention. Am J Cardiol. 2007;100:203-5.

188. Hochholzer W, Trenk D, Fromm MF, et al. Impact of cytochrome P450 2C19 loss-of-function polymorphism and of major demographic characteristics on residual platelet function after loading and maintenance treatment with clopidogrel in patients undergoing elective coronary stent placement. J Am Coll Cardiol. 2010:55:2427-34.

189. de Man FH, Nieuwland R, van der Laarse A, et al. Activated platelets in patients with severe hypertriglyceridemia: effects of triglyceridelowering therapy. Atherosclerosis. 2000;152:407-14.

190. Pedreño J, Hurt-Camejo E, Wiklund O, Badimón L, Masana L. Platelet function in patients with familial hypertriglyceridemia: evidence that platelet reactivity is modulated by apolipoprotein $\mathrm{E}$ content of verylowdensity lipoprotein particles. Metabolism. 2000:49:942-9.

191. Olufadi R, Byrne CD. Effects of VLDL and remnant particles on platelets. Pathophysiol Haemost Thromb. 2006:35:281-91.

192. Kuhn FE, Mohler ER, Satler LF, Reagan K, Lu DY, Rackley CE. Effects of high-density lipoprotein on acetylcholine-induced coronary vasoreactivity. Am J Cardiol. 1991;68:1425-30.

193. Spieker LE, Sudano I, Hürlimann D, et al. High-density lipoprotein restores endothelial function in hypercholesterolemic men. Circulation. 2002;105:1399-402

194. Calkin AC, Drew BG, Ono A, et al. Reconstituted high-density lipoprotein attenuates platelet function in individuals with type 2 diabetes mellitus by promoting cholesterol efflux. Circulation. 2009;120:2095-104

195. Lim HS, Blann AD, Lip GY. Soluble CD40 ligand, soluble P-selectin, interleukin-6, and tissue factor in diabetes mellitus: relationships to cardiovascular disease and risk factor intervention. Circulation. 2004;109:2524-8.

196. Calverley DC, Hacker MR, Loda KA, et al. Increased platelet Fc receptor expression as a potential contributing cause of platelet hypersensitivity to collagen in diabetes mellitus. Br J Haematol. 2003;121:139-42.

197. Belostocki K, Pricop L, Redecha PB, et al. Infliximab treatment shifts the balance between stimulatory and inhibitory Fcgamma receptor type II isoforms on neutrophils in patients with rheumatoid arthritis. Arthritis Rheum. 2008;58:384-8.

198. Kansas GS. Selectins and their ligands: current concepts and controversies. Blood. 1996;88:3259-87.

199. Galajda P, Baláž D, Šutarík L', Mokáň M, Kubisz P. P-selectin in patients with diabetes mellitus. Hematol Transfuziol. 1998;8:21-4.

200. Jilma B, Fasching P, Ruthner $C$, et al. Elevated circulating P-selectin in insulin dependent diabetes mellitus. Thromb Haemost. 1996;76:328-32.

201. Kopp HP, Hopmeier P, Schernthaner G. Concentrations of circulating P-selectin are increased in patients with newly diagnosed insulin-dependent diabetes mellitus. Exp Clin Endocrinol Diabetes. 1998:106:41-4

202. Blann AD, Dobrotova M, Kubisz P, McCollum CN. Von Willebrand factor, soluble P-selectin, tissue plasminogen activator and plasminogen activator inhibitor in atherosclerosis. Thromb Haemost. 1995;74:626-30.

203. Lip GY, Blann AD, Zarifis J, Beevers M, Lip PL, Beevers DG. Soluble adhesion molecule P-selectin and endothelial dysfunction in essential hypertension: implications for atherogenesis? A preliminary report. J Hypertens. 1995;13:1674-8. 
204. Blann AD, Lip GY, Beevers DG, McCollum CN. Soluble P-selectin in atherosclerosis: a comparison with endothelial cell and platelet markers. Thromb Haemost. 1997;77:1077-80.

205. Galajda P, Baláž D, Vladár L', Ivanková J, Mokáň M. Dysfunction of platelets in patients with diabetes mellitus (diabetic thrombocytopathy). Slov Lek 1998; 8:18-21.

206. Blann AD, Lanza F, Galajda P, et al. Increased platelet glycoprotein $\checkmark$ levels in patients with coronary and peripheral atherosclerosisthe influence of aspirin and cigarette smoking. Thromb Haemost. 2001:86:777-83

207. Kubisz P, Arabi A, Holan J, Cronberg S. Investigations on platelet function in diabetes mellitus. Haemostasis. 1984;14:347-53.

208. Abdelwhab S, Fooda O, Abdelmaksoud S. Thrombospondin-1 in patients with diabetic nephropathy. Kidney. 2010;19:229-35.

209. Freynhofer MK, Gruber SC, Grove EL, Weiss TW, Wojta J, Huber K. Antiplatelet drugs in patients with enhanced platelet turnover: biomarkers versus platelet function testing. Thromb Haemost. 2015;114:459-68

210. Clemetson KJ. Platelets and primary haemostasis. Thromb Res. 2012;129:220-4

211. Woo KS, Kim BR, Kim JE. Determination of the prevalence of aspirin and clopidogrel resistances in patients with coronary artery disease by using various platelet-function tests. Korean J Lab Med. 2010;30:460-8.

212. Lacroix R, Dubois C, Leroyer AS, Sabatier F, Dignat-George F. Revisited role of microparticles in arterial and venous thrombosis. JThromb Haemost. 2013;11:24-35.

213. Gremmel T, Ay C, Riedl J, et al. Platelet-specific markers are associated with monocyte-platelet aggregate formation and thrombin generation potential in advanced atherosclerosis. thromb Haemost. 2016:115:615-21.

214. Mitsui C, Kajiwara K, Hayashi $H$, et al. Platelet activation markers overexpressed specifically in patients with aspirin-exacerbated respiratory disease. J Allergy Clin Immunol Pract. 2016;137:400-11.

215. Pfluecke C, Berndt K, Wydra S, et al. Atrial fibrillation is associated with high levels ofmonocyte-platelet-aggregates and increased CD11b expression in patients with aortic stenosis. Thromb Haemost. 2016:115:1-8.

216. Kodiatte TA, Manikyam UK, Rao SB, et al. Mean platelet volume in type 2 diabetes mellitus. J Lab Physicians. 2012;4:5-9.

217. Swaminathan A, Amitkumar K, Ganapathy S, Ayyavoo S. Evaluation of mean platelet volume and other platelet parameters in subjects with type-2 diabetes mellitus. Natl J Physiol Pharm Pharmacol. 2017;7:51.

218. Buch A, Kaur S, Nair R, Jain A. Platelet volume indices as predictive biomarkers for diabetic complications in type 2 diabetic patients. J Lab Physicians. 2017;9:84-8.

219. Shah B, Sha D, Xie D, Mohler ER, Berger JS. The relationship between diabetes, metabolic syndrome, and platelet activity as measured by mean platelet volume: the National Health And Nutrition Examination Survey, 1999-2004. Diabetes Care. 2004;35:1074-8.

220. Davi G, Gresele P, Violi F, et al. Diabetes mellitus, hypercholesterolemia, and hypertension but not vascular disease per se are associated with persistent platelet activation in vivo. Evidence derived from the study of peripheral arterial disease. Circulation. 1997;96:69-75.

221. Davi G, Ciabattoni G, Consoli A, et al. In vivo formation of 8-iso-prostaglandin F2a and platelet activation in diabetes mellitus: effects of improved metabolic control and vitamin E supplementation. Circulation. 1999:99:224-9.

222. Orbe J, Rodríguez JA, Calvayrac $\mathrm{O}$, et al. Matrix metalloproteinase-10 is upregulated by thrombin in endothelial cells and increased in patients with enhanced thrombin generation. Arterioscler Thromb Vasc Biol. 2009:29:2109-16.

223. Mallat Z, Benamer $\mathrm{H}$, Hugel $\mathrm{B}$, et al. Elevated levels of shed membrane microparticles with procoagulant potential in the peripheral circulating blood of patients with acute coronary syndromes. Circulation. 2000;101:841-3.

224. Romano M, Pomilio M, Vigneri S, et al. Endothelial perturbation in children and adolescents with type 1 diabetes: association with markers of the inflammatory reaction. Diabetes Care. 2001;24:1674-8.

225. Bernal-Mizrachi L, Jy W, Jimenez JJ, et al. High levels of circulating endothelial microparticles in patients with acute coronary syndromes. Am Heart J. 2003;145:962-70.
226. Min PK, Cho M, Hong SY, et al. Circulating microparticles and coronary plaque components assessed by virtual histology intravascular ultrasound of the target lesion in patients with stable angina. PLOS ONE. 2016;11:e0148128.

227. Choi JL, Li S, Han JY. Platelet function tests: a review of progresses in clinical application. Biomed Res Int. 2014;2014:456569.

228. Fuentes E, Palomo I, Alarcón M. Platelet miRNAs and cardiovascular diseases. Life Sci. 2015;133:29-44.

229. Pordzik J, Pisarz K, De Rosa S, et al. The potential role of platelet-related micrornas in the development of cardiovascular events in high-risk populations, including diabetic patients: a review. Front Endocrinol. 2018;9:74.

230. Wang B, Aw TY, Stokes KY. N-acetylcysteine attenuates systemic platelet activation and cerebral vessel thrombosis in diabetes. Redox Biol. 2018;14:218-28.

231. Koenig-Oberhuber $V$, Filipovic M. New antiplatelet drugs and new oral anticoagulants. Br J Anaesth. 2016;117(Suppl 2):ii74-84.

232. Patrono C, Andreotti F, Arnesen $\mathrm{H}$, et al. Antiplatelet agents for the treatment and prevention of atherothrombosis. Eur Heart J. 2011:32:2922-32.

233. Fuster V, Sweeny JM. Aspirin: a historical and contemporary therapeutic overview. Circulation. 2011:123:768-78.

234. Oprea AD, Popescu WM. Perioperative management of antiplatelet therapy. Br J Anaesth. 2013;111(Suppl 1):i3-17.

235. Hall R, Mazer CD. Antiplatelet drugs: a review of their pharmacology and management in the perioperative period. Anesth Analg. 2011:112:292-318.

236. Michelson AD. Advances in antiplatelet therapy. Hematol Am Soc Hematol Educ Program. 2011;2011:62-9.

237. Weitz JI, Eikelboom JW, Samama MM, American College of Chest Physicians. Newantithrombotic drugs: antithrombotic therapy and prevention of thrombosis, 9th ed: American College of Chest Physicians evidence-based clinical practice guidelines. Chest. 2012;141(2 Suppl):e120S-51S.

238. Ogawa H, Nakayama M, Morimoto T, et al. Japanese Primary Prevention of Atherosclerosis With Aspirin for Diabetes (JPAD) Trial Investigators. Low-dose aspirin for primary prevention of atherosclerotic events in patients with type 2 diabetes: a randomized controlled trial. JAMA. 2008;300:2134-41.

239. Scaglione F. New oral anticoagulants: comparative pharmacology with vitamin K antagonists. Clin Pharmacokinet. 2013;52:69-82.

240. Mendonca S, Gupta D, Valsan A, Tewari R. Warfarin related acute kidney injury: a case report. Indian J Nephrol. 2017;27:78-80.

241. Trailokya A, Hiremath JS, Sawhney JPS, Mishra YK, Kanhere V, Srinivasa $R$, et al. Acenocoumarol: a review of anticoagulant efficacy and safety. J Assoc Physicians India. 2016;64:88-93.

242. Behera SK, Xavier AS, Selvarajan S, Munuswamy H, Haridasan S, Srinivas $\mathrm{BH}$. Acenocoumarol as an alternative anticoagulant in a patient with warfarin-related nephropathy. Br J Clin Pharmacol. 2018;84:1068-71.

243. Weitz Jl, Lensing AW, Prins MH, et al. Rivaroxaban or aspirin for extended treatment of venous thromboembolism. N Engl J Med. 2017;376:1211-22.

244. Topol EJ, Byzova TV, Plow EF. Platelet GPIIb-IIla blockers. Lancet 1999;353:227-31.

245. Lele M, Sajid M, Wajih N, Stouffer GA. eptifibatide and 7E3, but not tirofiban, inhibit av $\beta 3$ integrin-mediated binding of smooth muscle cells to thrombospondin and prothrombin. Circulation. 2001;104:582-7.

246. Zhou X, Wu X, Sun H, Li J. Efficacy and safety of eptifibatide versus tirofiban in acute coronary syndrome patients: a systematic review and meta-analysis. J Evid Based Med. 2017;10:136-44.

247. Eikelboom JW, Weitz JI. New anticoagulants. Circulation. 2010:121:1523-32.

248. Garcia DA, Baglin TP, Weitz Jl, Meyer M. Parenteral anticoagulants: antithrombotic therapy and prevention of thrombosis, 9th ed: American College of Chest Physicians evidence evidencebased clinical practice guidelines. Chest. 2012;141:e24S-43S. 